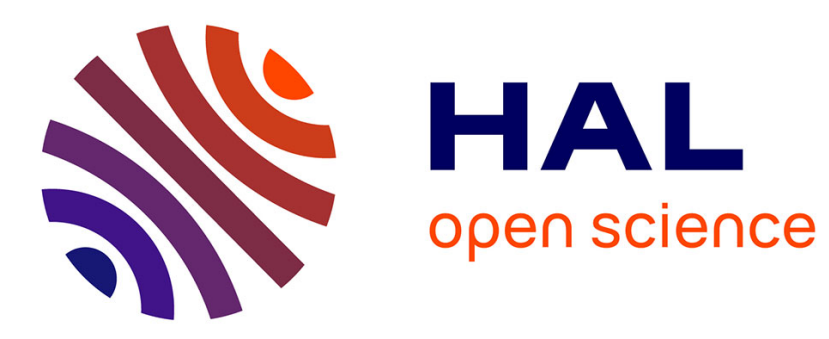

\title{
Drop Impact on a Solid Surface
}

C Josserand, S T Thoroddsen

\section{To cite this version:}

C Josserand, S T Thoroddsen. Drop Impact on a Solid Surface. Annual Review of Fluid Mechanics, 2016, 48, pp.365 - 391. 10.1146/annurev-fluid-122414-034401 . hal-01398138

\section{HAL Id: hal-01398138 https://hal.science/hal-01398138}

Submitted on 24 Jan 2017

HAL is a multi-disciplinary open access archive for the deposit and dissemination of scientific research documents, whether they are published or not. The documents may come from teaching and research institutions in France or abroad, or from public or private research centers.
L'archive ouverte pluridisciplinaire HAL, est destinée au dépôt et à la diffusion de documents scientifiques de niveau recherche, publiés ou non, émanant des établissements d'enseignement et de recherche français ou étrangers, des laboratoires publics ou privés. 


\section{Drop Impact on a Solid Surface}

\section{Josserand ${ }^{1}$ and S. T. Thoroddsen ${ }^{2}$}

${ }^{1}$ Sorbonne Universités, CNRS \& UPMC Univ. Paris 06, UMR 7190, Institut D'Alembert, F-75005 Paris, France

${ }^{2}$ Division of Physical Sciences and Engineering \& Clean Combustion Research Center, King Abdullah University of Science and Technology (KAUST),

Thuwal, 23955-6900, Saudi Arabia

Xxxx. Xxx. Xxx. Xxx. YYYY. 00:1-28

This article's doi:

$10.1146 /(($ please add article doi) $)$

Copyright (C) YYYY by Annual Reviews. All rights reserved

\section{Keywords}

splashing, spreading, bouncing, fingering, air entrapment, roughness, repellency, superhydrophobicity

\section{Abstract}

A drop hitting a solid surface, can deposit, bounce or splash. Splashing arises from the breakup of a fine liquid sheet which is ejected radially along the substrate. Bouncing and deposition depend crucially on the wetting properties of the substrate. In this review we focus on recent experimental and theoretical studies, which aim at unraveling the underlying physics, characterized by the delicate interplay of not only liquid inertia, viscosity and surface tension, but also the surrounding gas. The gas cushions the initial contact, it is entrapped into a central microbubble on the substrate and it promotes the so-called coronasplash, by lifting the lamella away from the solid. Particular attention is paid to the influence of surface roughness, natural or engineered to enhance repellency, relevant in many applications. 

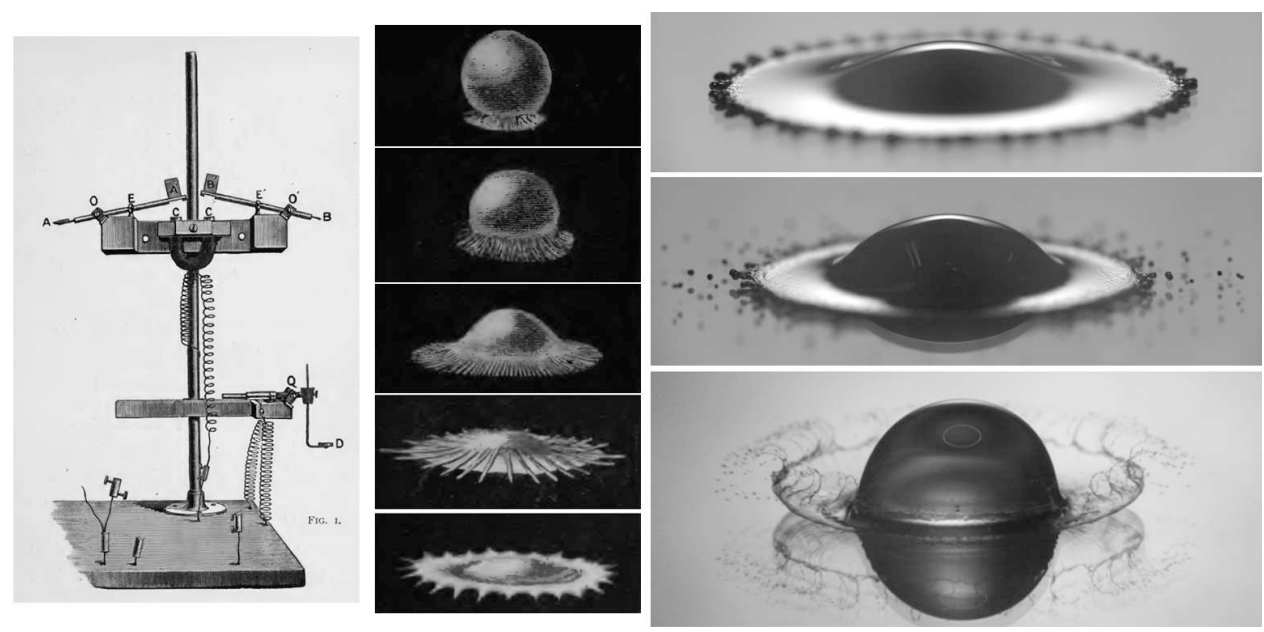

Figure 1

(a) Worthington's drop-release setup and (b) his sketches of an impacting mercury drop. (c) Using modern video technology for mercury on glass under similar impact conditions. (d) Prompt splash for mercury drop impacting superhydrophobized glass and (e) corona splash for ethanol drop on glass (courtesy of Erqiang Li). See also supplemental video clips.

First images of drop splashing : trace back to the dawn of photography by Worthington

\section{INTRODUCTION}

The fingering of an ink-blot or a coffee stain is familiar to everyone. However, despite 140 years of study (Worthington (1876)), the underlying rapid dynamics of the impact process eluded explanation until the last 20 years, when high-speed video technology began to allow time-resolved observations of this intriguing phenomenon (Thoroddsen et al. (2008)). The increasing pace of sensor improvements and availability is allowing study of ever finer detail, as well as is reinvigorating research in this area of study, as is demonstrated by the publication years of the references cited herein. This imaging technology is now reaching the diffraction limit of spatial resolution and sub-microsecond interframe times (Visser et al. (2015); Li \& Thoroddsen (2015)). This is being matched by, increasing computation power and improved numerical algorithms, to allow fully resolved simulations, in the axisymmetric configuration (Thoraval et al. (2012)), while fully 3-D cases, from first contact, should soon follow (Agbaglah et al. (2011)).

We strictly confine our review to impacts onto solid surfaces and leave out studies involving impacts onto pools or films of liquid. Moreover, we emphasize recent works, i.e. appearing after the earlier Annual Review by Yarin (2006), which dealt with impacts on both solid and liquid surfaces.

Studies of drop impacts are driven by a large number of areas of relevance both in nature and industry. In nature, the drop hollows the stone, splashing produces aerosols, cause erosion and bring the smell of the earth during rain (Recent Nature paper?). Industrial relevance includes, spray/wall interactions in coating, cleaning, cooling and combustion. Inkjet droplets play an increasing role in fabrication, from soldering of electronics to microarrays in biotechnology.

In Figure 1 we show some of the iconic images of impacting drops, which are in fact sketches done by Worthington around the dawn of photography. He used an ingenious 
mechanical contraption, with spark illumination, triggered by a marble falling in tandem with the drop. He then drew up his flash illuminated visions of the impact of a mercury drop, as shown in Figure 1b, seeing interesting finger-like spokes on the spreading lamella. However, using modern technology we have reproduced his impact conditions, i.e. 1/15 inch drop diameter and impact height of 3 inches, but see no such radial spokes, Figure 1c. One possible explanation is the soot which he used to superhydrophobize his spectacle glass for releasing the drop (soot also works well as an oleophobic coating, see Deng et al. (2012)). This might have formed a coating on the drop, or an oxidized layer may have formed, or simply the flash duration was too long and smeared out the edge-bumps into radial streaks, as was suggested in the celebrated review of Rein (1993).

\subsection{The canonical impact}

In order to define the different parameters involved in drop impacts we will consider as the prototype the normal impact of a spherical liquid drop on a flat solid substrate. The drop diameter is $D=2 R$ and the normal impact velocity $V$. The liquid and surrounding gas have densities $\rho_{l}$ and $\rho_{g}$, dynamical (kinematic) viscosities $\mu_{l}\left(\nu_{l}=\mu_{l} / \rho_{l}\right)$ and $\mu_{g}\left(\nu_{g}=\mu_{g} / \rho_{g}\right)$ respectively. The surface tension is denoted $\gamma$ and the gravity $g$, which is oriented along the vertical direction.

As stated, the canonical impact problem depends a priori on five dimensionless parameters. In fact, considering the balance between the gravity and the inertia through the Froude number $F r=V / \sqrt{g D}$ one can show that gravity can be neglected. Indeed, for usual impact conditions $F r \gg 1$ so that only four dimensionless parameters are pertinent for the impact dynamics although the gravity plays a crucial role in the experiment to accelerate the drop until its impact velocity. In general, the impact dynamics is first characterized by the Reynolds and Weber numbers defined with the liquid properties as:

$$
R e=\frac{\rho_{l} D V}{\mu_{l}} \text { and } W e=\frac{\rho_{l} D V^{2}}{\gamma},
$$

which balance the inertia with the viscous and the capillary forces respectively. Alternatively these two numbers, the Ohnesorge and the capillary numbers are often used in the literature, yielding

$$
O h=\frac{\mu_{l}}{\sqrt{\rho_{l} D \gamma}}=\frac{\sqrt{W e}}{R e}, \text { and } C a=\frac{\mu_{l} V}{\gamma}
$$

In addition to these numbers are the two ratio of the liquid-gas densities and viscosities, $\rho_{l} / \rho_{g}$ and $\mu_{l} / \mu_{g}$. In order to quantify the influence of the gas in the lubrication layer beneath the drop before the impact, it is convenient to introduce instead of the viscous ratio the Stokes number:

$$
S t=\frac{\mu_{g}}{\rho_{l} D V}=\frac{\mu_{g}}{\mu_{l}} \cdot \frac{1}{R e}
$$

Finally, other dimensionless parameters can be present in the dynamics, often hidden in the literature, and related to the drop shape (aspect ratio of the drop at impact for instance) or the substrate properties (contact angle $\theta_{e}$ and roughness distribution in particular).

Reynolds number: $R e=\frac{\rho_{l} D V}{\mu_{l}}$

Weber number: $W e=\frac{\rho_{l} D V^{2}}{\gamma}$

Ohnesorge number: $O h=\frac{\mu_{l}}{\sqrt{\rho_{l} D \gamma}}$ Capillary number: $C a=\frac{\mu_{l} V}{\gamma}$

Stokes number: $S t=\frac{\mu_{g}}{\rho_{l} D V}$ 

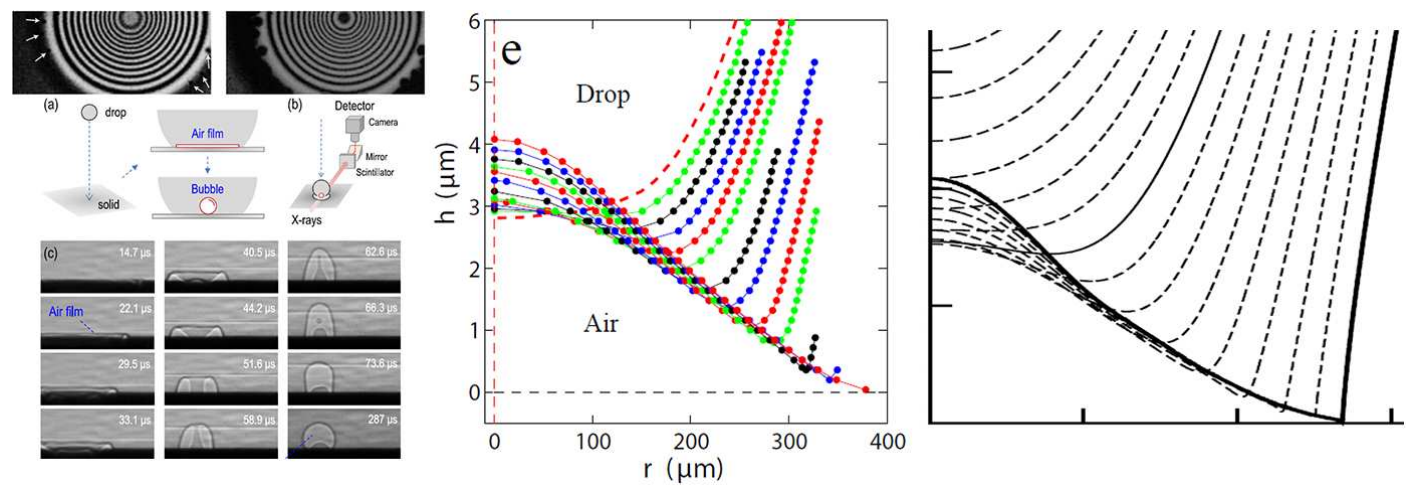

Figure 2

(a) Examples of interference patterns of the central air disc, taken from Liu et al. (2013). (b) X-ray imaging of the entrapment of an air-disc and its contraction into an air bubbles with a sub-satellite pinched off at it center (Lee et al. (2012)). (c) Examples of central air-disc shape during the approach of the drop and contact with the substrate, at impact velocity $V=1.06 \mathrm{~m} / \mathrm{s}$, from Li \& Thoroddsen (2015). (d) Compared to the theory of Hicks \& Purvis (2013).

\section{EARLY CONTACT: CENTRAL BUBBLE AND SKATING ON AIR}

\subsection{Central bubble}

Under atmospheric conditions, a drop impacting perpendicularly to a wall will always entrap a small air bubble under its center. The drop approaches the solid surface inside a gas which must be displaced before contact. When the drop gets close to the surface, the lubrication pressure in the thin air layer due to the gas viscosity becomes strong enough to deform its bottom into a dimple and thereby transforming a point contact into one along a ring, with a thin disk of air entrapped. The air-disk contracts rapidly into a central bubble on the substrate, to minimize surface energy. This bubble was observed in the snapshots of Chandra \& Avedisian (1991), Thoroddsen \& Sakakibara (1998) and under inkjet droplets by Van Dam \& Le Clerc (2004), but without clear explanation of its formation. Thoroddsen et al. (2005) used high-speed video to observe directly the initial air-disk and its contraction. Measuring the volume of air in the resulting bubble, they could estimate the initial average thickness of the air-disk, as being in the range $\bar{\delta} \sim 2-5 \mu \mathrm{m}$. The contraction speed was successfully modelled with capillary-inertial dynamics, by assuming that the layer is uniform but increases in thickness during the reduction in radius. This gives an expression for the disc radius vs time, $R=R_{o} \exp \left[-C \sqrt{\pi \sigma / \rho \Omega_{b}} t\right]$, in close agreement with the measurements. Here the constant $C \simeq 0.94$ and $\Omega_{b}$ is the bubble volume. However, the edge of the contracting air sheet thickens and thereby the disk is not of uniform thickness. This is perhaps most clearly visible in the $X$-ray imaging of Lee et al. (2012). This lead Liu et al. (2013) to improve upon the above expression, adding corrections to the contraction rate.

Recent advances have applied high-speed interferometry to directly measure the radial thickness profile of the air disc. Interferometry fringes can easily give radial changes in the layer thickness, with $\lambda / 4 \sim 150 \mathrm{~nm}$ resolution between a dark and a bright fringe (Driscoll \& Nagel (2011); Driscoll et al. (2010); Liu et al. (2013)). However, to get absolute thicknesses, more sophisticated methods must be applied, including two-colour techniques (de Ruiter et al. (2012)) and white-light interferometry (van der Veen et al. (2012)). The 
two-colour technique can give extraordinary sub-fringe thickness resolution of about $30 \mathrm{~nm}$ (de Ruiter et al. (2015a)). These techniques have primarily been applied for low impact velocities, specifically to study bouncing dynamics (de Ruiter et al. (2015b)). However, using $50 \mathrm{~ns}$ laser-pulses for each video frame, interferometry can be realized at $5 \mathrm{Mfps}(\mathrm{Li}$ \& Thoroddsen (2015)), to obtain time-resolved evolution of the air-layer profile for higher impact velocities, as shown in Figure 2c.

The contraction of the air-disc into the central bubble is also not without surprises. Thoroddsen et al. (2005) showed that the retracting edge produces capillary waves, which propagate towards the center. Sometimes the apex of this converging wave touches the substrate at the axis of symmetry and pinches off a micro-drop within the central bubble, as shown in Figure 2. These proposed dynamics were verified by Lee et al. (2012) using $\mathrm{X}$-ray imaging of the process, in Figure $\mathbf{2 b}$. Their images even reveal a subsatellite formed inside the bubble inside the drop.

\subsection{Modeling the air-layer thickness}

The deformation of the bottom of the drop, the dimple formation and subsequent entrapment of the air-disc is governed by a balance between drop inertia and the lubrication pressure in the air, which tries to escape the oncoming drop. The modeling of the airlayer cushioning was started by looking at 2-D cases (Smith et al. (2003); Korobkin et al. (2008)), later adapted to the axisymmetric configuration, which exhibits the same scaling (Hicks \& Purvis (2010)). Here the dynamics assume viscous lubrication pressure in the air-layer, which for small separation distances starts to deform the drop inviscidly. These rapid motions can neglect surface tension, liquid viscosity and gravity. The dimensional argument is essentially the following: The separation distance $H$ between drop and solid, must become small enough to make the lubrication pressure in this thin air layer $P \sim \mu_{g} V R / H^{2}$ become strong enough to rapidly decelerate the bottom tip of the drop. There, the horizontal/radial scaling used is $\sqrt{D H}$, coming from geometrical arguments. The deceleration $a$ occurs over this distance $H$, in the very short available time $\tau \sim H / V$, giving $\rho_{l} a \sim \rho_{l} V / \tau \sim \rho_{l} V^{2} / H$. Equating these two effects gives a characteristic thickness for start of drop deformation involving the Stokes number $H^{*}=R S t^{2 / 3}$.

This allowed quantitative comparison to experiments: for example the prediction of the initial radius of the contact ring (Hicks et al. (2012))

$$
L_{o}=3.8\left(\frac{4 \mu_{g}}{\rho_{\ell} V}\right)^{1 / 3} R^{2 / 3}
$$

is in reasonable agreement with available data (Liu et al. (2013); Thoroddsen et al. (2005)), without any adjustable constants, but one must use the bottom radius of curvature of the falling drop for $R$.

\subsection{Gas Compressibility}

Building on the previous incompressible theory (Korobkin et al. (2008); Smith et al. (2003)), Mandre et al. (2009) found conditions, for higher impact velocities, when the compressibility of the gas will come into play. This effect is included in the lubrication equation for the gas in a low-Mach number approximation and is expressed in terms of a 
compressibility factor

$$
\epsilon=\frac{P_{a t m}}{\left(R V^{7} \rho_{\ell}^{4} / \mu_{g}\right)^{1 / 3}} .
$$

If $\epsilon^{-1}>\sim 5$ one expects compression of the air-disc and smaller values of $H^{*}$. This thinning should scale as $H^{*} /\left(R_{b} S t^{2 / 3}\right)=3.2 \epsilon^{1 / 3}$. Li \& Thoroddsen (2015) have recently carried out interferometry experiments for $\epsilon^{-1}$ as high as 40, verifying this theory and the corresponding numerics of Mandre et al. (2009). The measured disc thickness, at the centerline, is as thin as $H^{*} \sim 0.5 \mu \mathrm{m}$.

Hicks \& Purvis (2013) added more thermodynamics into the equation-of-state for the gas. Furthermore, while their compressible theory is limited to 2-D, they showed that $L_{o}$ is not dependent on the gas compressibility. This is indeed born out by Li \& Thoroddsen (2015), where they find a perfect fit of $L_{o}$ to the above expression (1), over a large range of impact values, well into the compressible regime. This contradicts earlier results by Liu et al. (2013), where smaller water drops were used and $L_{o}$ was essentially independent of $V$.

The thinning of the air-film should continue at even higher impact velocities. Indeed, perhaps surprisingly, single central bubbles are observed in the snapshots of Mehdizadeh et al. (2004) for $V$ as high as $40 \mathrm{~m} / \mathrm{s}$, where $\epsilon^{-1} \simeq 1360$ (Figure 7). The corresponding air-disc thickness is predicted to be $H^{*} \simeq 15 \mathrm{~nm}$, where one might expect molecular forces to break up the air-layer before contraction into the bubble.

\subsection{Size of the entrapped bubble}

The size of entrapped air bubble is important in inkjet-based fabrication, as it can have detrimental effects on uniformity, conductance etc. For minuscule impact velocities the lubricating air film can become unstable and break the axisymmetry, allowing the air to escape, see Klaseboer et al. (2000). The lowest velocities can also lead to isolated contacts and spreading with minimal air entrapment (Kolinski et al. (2012); de Ruiter et al. (2015b)). Bouwhuis et al. (2012) applied interferometry to investigate the size of the entrapped air layer and found a maximum, which occurs at a moderate impact velocity, where compressibility can be ignored. This arises due to competition between surface tension and inertia of the liquid. For low enough impact velocities, the surface tension minimizes the drop deformation away from spherical shape and $H^{*} \sim S t^{-1 / 2}$, while at higher velocities inertia dominates and the dynamic pressure grows as square of velocity thereby draining out more air, which reduces $H^{*} \sim S t^{2 / 3}$ in agreement with Mandre et al. (2009). In between these two considerations is a maximum, with a cross-over at $S t_{c} \sim C a_{g}^{3 / 4}$ (where $C a_{g}=\mu_{g} V / \gamma$ is the capillary number based on the gas viscosity) or expressed in a critical impact velocity $V_{c} \sim\left(\mu_{g} \sigma^{3} / \rho_{\ell}^{4} R^{4}\right)^{1 / 7}$. For their ethanol drop, of $R=0.9 \mathrm{~mm}, V_{c}=0.25 \mathrm{~m} / \mathrm{s}$. Klaseboer et al. (2014) have proposed a different power-law for the large-impact-velocity regime, $H \sim S t^{1 / 2}$, arising from using a different velocity potential in the drop than in Bouwhuis et al. (2012).

Hendrix et al. (2015) propose a model unifying three impact configurations, i.e. drop onto solid, solid sphere onto pool (Marston et al. (2011)), as well as a drop onto pool, showing that the normalized bubble volume $V_{b} / V_{\text {drop }} \sim S t^{4 / 3}$. However, for the last configuration, twice as much volume is entrapped, or one must use half the impact velocity, owing to the two compliant surfaces arising from the added mass of the pool. 


\section{5. 'Skating on a thin layer of air' or contact with the solid substrate}

One of the interesting questions the above studies have raised, is the detailed breakup of the air-layer, when molecular contact is first established with the solid substrate. Motivated by the effect of air pressure on the splashing, Mandre et al. (2009) suggested the drop might slide on a continuous layer of air and splash without molecular contact. Kolinski et al. (2012) used Total Internal Reflection (TIR) to support this notion and coined the phrase "skating on a film of air". The TIR technique observes the gracing light reflected from a glass surface, when the angle between the incident light and the glass surface is smaller than a critical angle ( $48^{\circ}$ for air-glass). However, when the liquid makes contact with the glass surface, due to the similar refractive index of the glass and liquid, the reflection disappears and the contacts become clearly marked by dark spots. Some signature is also observed due to an evanescent wave, when the air-layer becomes a few tens of nano-meters, allowing measurements of the bottom profile of the drop (Kolinski et al. (2014)).

Following much debate, this issue can be clarified by the following observations: First of all, the contraction of the central disc into the bubble would not occur without a contact-line, which must be present to allow reduction in surface energy (Thoroddsen et al. (2005)). Secondly, Driscoll \& Nagel (2011) used optical interference technique to show that for higher impact velocities, the liquid contact outside the central disk, wets the substrate. Their measurements show that if there were a thin air-layer present, it must be less than $3.5 \mathrm{~nm}$ thick. Such layer would of course be highly unstable by van der Waals interactions. Thirdly, Kolinski et al. (2012) (see also Kolinski et al. (2014); de Ruiter et al. (2015a)) showed clearly the formation of isolated wetting contacts and that increasing the impact velocity causes larger number of contacts along the ring bounding the central disc. One can speculate that even higher velocities will show still more numerous contacts and transition to what appears like a continuous rupture. The characteristic dark ring marking the initial contact radius, seen by Thoroddsen et al. $(1998,2005)$ and more recently by de Ruiter et al. (2015a) are likely a micro-bubble signature of this initial contact. The effects of statistical roughness and isolated asperities remains an open question, as was discussed by Mani et al. (2010) and Mandre \& Brenner (2012). Common feature of many of the imaging of the early contact through grass plates, is a number of isolated contacts, see for example Liu et al. (2013). These are most likely due to local asperities, which become important when the air layer thickness reaches down to dozens of nanometers. This needs to be further studied with glass substrates which have been well-characterized before the impact. These details will not change the final outcome, but would give a strong indication of the actual air layer thickness when it ruptures, giving hints at the underlying physics, be they hydrodynamic or molecular in nature.

On the other hand, for the lowest impact velocities the drops can indeed glide on a film of air and rebound without contacting the solid substrate, even for hydrophilic surfaces (Kolinski et al. (2014)). This has been studied in great detail by de Ruiter et al. (2015b) who have shown, in careful experiments, that skating for a water drop is only possible for $V<0.48 \mathrm{~m} / \mathrm{s}$. Over a range of liquids this corresponds to $W e<4$, while the minimum thickness observed $h_{m i n} \simeq 200 \mathrm{~nm}$. Furthermore, the scaling for $h_{m i n}$ derived from the axisymmetric simulations of Duchemin \& Josserand (2011) also shows that for impact velocities, of relevance in splashing, the thickness becomes sub-nanometric. One must therefore conclude that air skating under the center of the drop, is irrelevant for the splashing transition, discussed in the next section. 

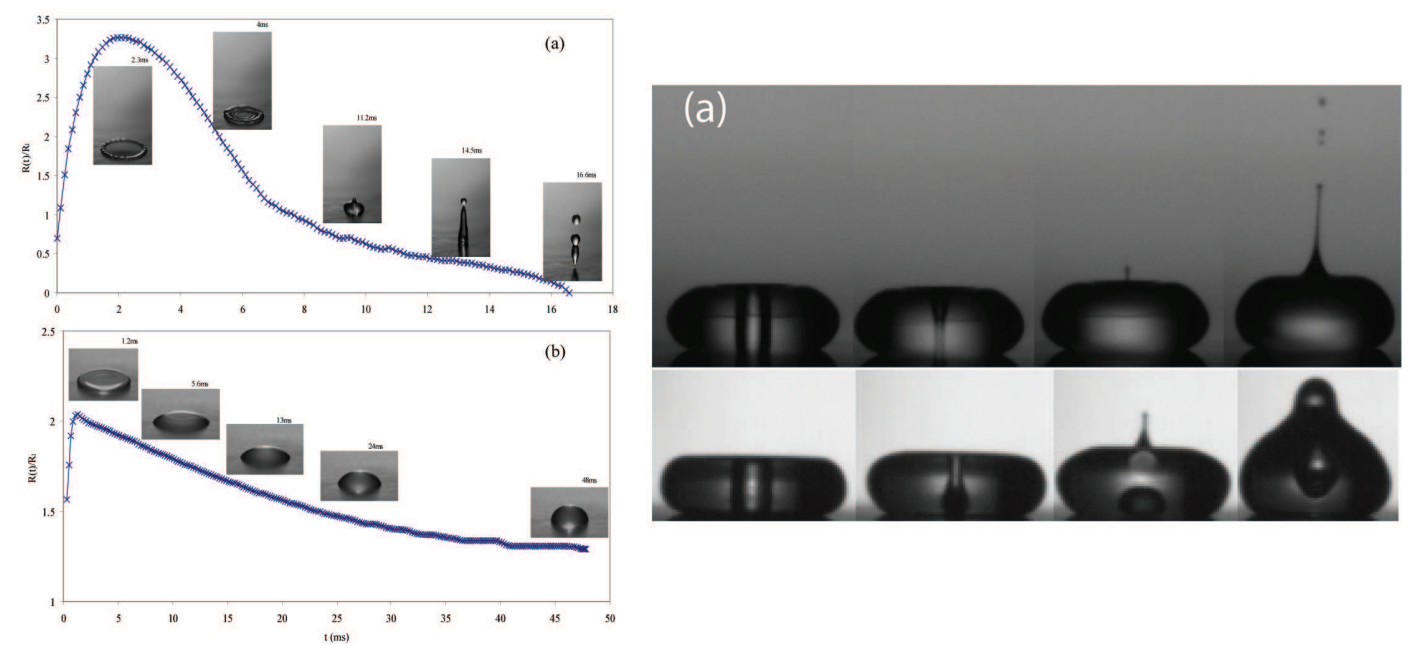

Figure 3

Left: Spreading and rebounding dynamics illustrated by snapshots as well as the evolution of the spreading radius with time, taken from Bartolo et al. (2005). Right:singular jet formed by the retraction after a small drop impacts on a super-hydrophobic surface, taken from Bartolo et al. (2006).

\section{LATER DYNAMICS: SPREADING AND REBOUNDING}

Later-time dynamics of the impact exhibit different behaviors depending on the impact and substrate parameters, ranging from smooth spreading to splashing, jetting and rebound. The spreading dynamics is an important aspect in many applications, for instance for inkjet printing in microelectronics (Minemawari et al. (2011)) or in forensic science (Attinger et al. (2013); Hulse-Smith et al. (2005); Laan et al. (2014)). In both cases, the splashingspreading transition is crucial for the printing quality or to determine the link between the blood pattern and drop trajectories.

\subsection{Overall spreading dynamics, rebound, jetting}

When no splashing is observed, the drop simply spreads over the surface until it reaches a maximum radius. Then, depending on the surface properties, the liquid can recede or remain close to this maximum spread (Rioboo et al. (2001)). The dynamics is then controlled by subtle balances between inertia, viscosity and capillary forces Bartolo et al. (2005). In particular, when the impact is performed on a (super)-hydrophobic surface the retraction of the drop can lead to partial or complete rebound and even to singular jet formation (Bartolo et al. (2006); Renardy et al. (2003)), as shown in Figure 3. This occurs through convergence of capillary waves at the apex, which can also entrap bubbles into the drop (Huang et al. (2013)). Pittoni et al. (2015) have tracked the various bubble entrapment mechanisms.

These retraction/rebound/jetting dynamics can be controlled by varying the wettability of the solid surface (Yokoi et al. (2009)). This is in particular the case when the impact is performed on textured surface: in such case, both the spreading dynamics and the retraction are affected depending whether the liquid penetrates the textured surface (Wenzel state) or move over the structures (Cassie-Baxter state) (Bartolo et al. (2006); Kwon et al. 
(2013); Maitra et al. (2014)). Furthermore, complex rebound and jetting dynamics can be observed when the drop impacts on an deformable solid surface such as an elastic membrane (Antkowiak et al. (2011)) or on fibers (Piroird et al. (2013)) for instance.

\subsection{Maximum/residual spreading radius, minimal thickness}

An important outcome of a drop impact on solid substrate is the maximum spreading radius. This quantity, pertinent in the absence of splash, has applications in ink-jet printing Minemawari et al. (2011) or forensic science Attinger et al. (2013); Hulse-Smith et al. (2005) although in these cases the crucial quantity is the residual spreading radius, that can differ from the maximum spreading radius. Numerous relations relating the maximum spreading radius (or diameter) to the impact parameters have been established using physical argument based in general on the balance between inertia, viscous and capillary contributions (Chandra \& Avedisian (1991); Clanet et al. (2004); Eggers et al. (2010); Fedorchenko et al. (2005); Pasandideh-Fard et al. (1996); Roisman et al. (2002); Roisman (2009b); Ukiwe and Kwok (2005); Vadillo et al. (2009)). It is important to emphasize that all these relations show reasonable agreement with experiments and numerical simulations despite their quite different formulations. Indeed, for the ranges of parameters concerned, the spreading radius does not vary by many orders of magnitude so that power-law scalings are hard to identify and it is difficult to discriminate between the different models by quantitative arguments alone. Moreover, no asymptotic relation can be tested because of the splashing mechanism that occurs for large impact velocity, although these relations are often presented in such asymptotics form. In particular, the initial drop radius is often neglected so that some of these relations should be corrected by subtracting the initial drop radius.

However, most of these models distinguish two regimes for the spreading factor $\beta$, defined by the ratio between the maximum radius with the initial one:

$$
\beta=\frac{R_{M a x}}{R_{0}} .
$$

- A viscous regime where the maximal extension of the drop is obtained using a balance between the kinetic energy and the viscous dissipation. The spreading factor follows the relation: $\beta-1 \propto R e^{1 / 5}$, often simplified into

$$
\beta \propto R e^{1 / 5}
$$

- An inertial regime where the spreading factor is determined by a more complex balance between inertia and capillary forces with some correction due to viscous dissipation and wettability effects. Many different models have been proposed in this regime and their pertinence was still a question of scientific debate until recently. Firstly, a simple scaling analysis comparing the initial kinetic energy with the surface energy at the maximum spreading radius would suggest an asymptotic regime valid for large Weber numbers $\beta \propto W e^{1 / 2}$. However, as explained above, the available Weber numbers for this regime where no splash is present does not really allow to observe such scaling and more detailed models have included corrections due to the initial surface energy, contact angle and/or viscous dissipation. Finally, an alternative has been developed in Clanet et al. (2004) using a mass conservation argument based on the 
Table 1 Different models for the spreading factor $\beta$ as function of the impact parameters

\begin{tabular}{l|c|c}
\hline Model & Expression & Comment \\
\hline Scheller and Bousfield (1995) & $\begin{array}{c}\beta \sim 0.61\left(R e^{2} O h\right)^{1 / 6} \\
=0.61 R e^{1 / 5}\left(W e R e^{-2 / 5}\right)^{1 / 6}\end{array}$ & $\begin{array}{c}\text { Empirical law based } \\
\text { on experimental results. }\end{array}$ \\
\hline Pasandideh-Fard et al. (1996) & $\beta=\sqrt{\frac{W e+12}{3\left(1-\cos \theta_{a}\right)+4(W e / \sqrt{R e})}}$ & $\begin{array}{c}\text { Detailed energy balance, } \\
\text { including contact angle }\left(\theta_{a}\right), \\
\text { and initial conditions. }\end{array}$ \\
\hline Ukiwe and Kwok (2005) & $\beta^{3}\left(3\left(1-\cos \theta_{d}\right)+4 \frac{W e}{\sqrt{R e}}\right)$ & $\begin{array}{c}\text { Extension of above model } \\
\text { model, } \theta_{d} \text { being the dynamical } \\
\text { contact angle during spreading }\end{array}$ \\
\hline Clanet et al. (2004) & $\beta \propto W e^{1 / 4}$ & $\begin{array}{c}\text { Mass balance using the } \\
\text { impact capillary length. }\end{array}$ \\
\hline Eoisman (2009b) & $\beta \sim 0.87 R e^{1 / 5}$ & $\begin{array}{c}\text { Obtained using a dynamical } \\
\text { model for the spreading of the drop } \\
\text { involving a viscous boundary layer }\end{array}$ \\
\hline
\end{tabular}

pancake thickness selected by the capillary wave created by the impact and leading to the scaling law $\beta \propto W e^{1 / 4}$. This latter scaling law has had great success as it gives good quantitative agreement with experimental data for hydrophobic substrates and it has subsequently been commonly used to fitting experimental data. However it needs to be emphasized that the correction due to the initial radius (leading typically to consider $\beta-1$ instead of $\beta$ for the comparison for low Weber numbers) should be considered and would lower strongly the validity of this scaling. Quantitatively, as said above, all these formula give eventually good agreement with experimental and numerical data so that it is hard to discriminate between these different approaches. Table 1 presents the most commonly used formula in the literature to fit the experimental/numerical results.

Recently, dynamical models investigating the time evolution of a thin liquid film spreading on a solid substrate have given a general framework for the impact spreading that describes correctly the two regimes (viscous and inertial) and gives in particular a good understanding of the inertial regime conciliating most of the different existing models. Investigating the spreading dynamics after impact using thin film approximation was first proposed by Yarin \& Weiss (1995) and then adapted to different situations (Eggers et al. (2010); Fedorchenko et al. (2005); Roisman et al. (2009); Roisman (2009b)). Recently, the viscous boundary layer correction has been considered to the initial inviscid model, firstly by Roisman et al. (2009); Roisman (2009b) and later in a similar way by Eggers et al. (2010). The velocity in the spreading lamella can be described as a first approximation 

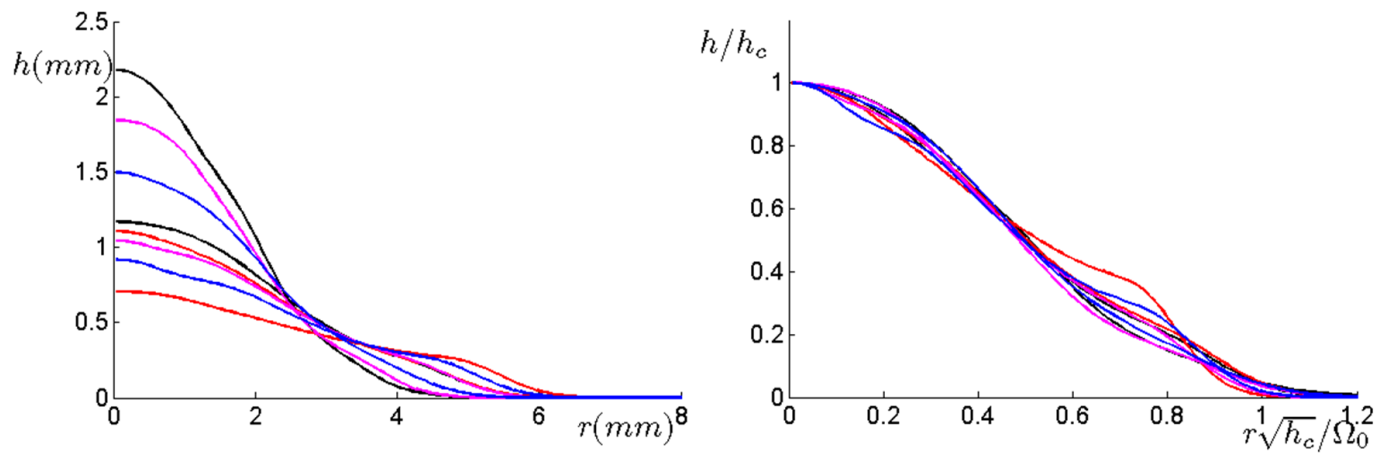

Figure 4

Experimental profile of a drop impacting a solid surface at different time (left) and then rescaled following eq. (4) (right), taken from Lagubeau et al. (2012).

by the following inviscid hyperbolic axisymmetric velocity field:

$$
v_{r}=\frac{r}{t} \text { and } v_{z}=-\frac{2 z}{t},
$$

that corresponds to a decreasing pressure field with time $\left(v_{r}\right.$ and $v_{z}$ being the radial and vertical velocities respectively). Such flow suggests that in this regime the drop surface (defined by $z=h(r, t)$ ) evolves in a self-similar way:

$$
h(r, t)=\frac{1}{t^{2}} H\left(\frac{r}{t}\right),
$$

that has been observed both in numerical simulations (Eggers et al. (2010); Roisman et al. (2009)) and experiments (Lagubeau et al. (2012)), as shown on Figure 4.

However, such Eulerian flow (eq. 3) is not consistent with the no-slip boundary condition on the substrate so that a time dependent viscous boundary layer develops from the substrate surface as the drop spreads. The thickness of this viscous layer obeys the usual scaling laws $\left(l_{b l} \sim \sqrt{\nu t}\right)$ and accounting for its dynamics allows for a better understanding of the overall drop spreading:

- The minimal liquid thickness experienced during the spreading follows (sometime called by extension the residual thickness):

$$
h_{\text {min }} \sim D R e^{-2 / 5}
$$

as observed numerically and experimentally, see Figure 5 a) (Eggers et al. (2010); Fedorchenko et al. (2005); Lagubeau et al. (2012); Roisman (2009b)).

- The spreading radius can be described through the value of an impact parameter $P=W e \cdot R e^{-2 / 5}$ following:

$$
\beta=R e^{1 / 5} f_{c}(P) .
$$

The function $f_{c}$ is expected to behave asymptotically as $P^{1 / 2}$ for small $P$ and as a constant for large $P$ in agreement with the inertia-capillary and inertia-viscous balance respectively. Although the inertia-capillary asymptotic limit cannot be investigated experimentally, this law confirms that it is the inertia/capillary balance that controls 

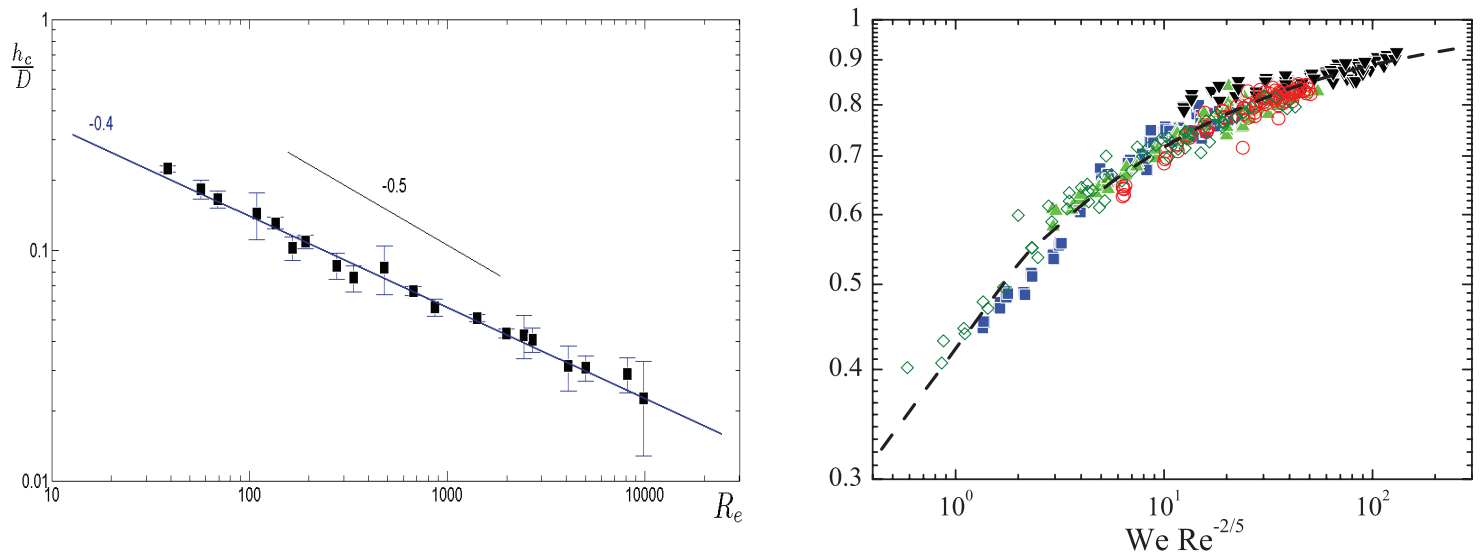

Figure 5

Left: minimal film thickness during the drop impact, compared to the predicted $R e^{-2 / 5}$ law eq. 5, taken from Lagubeau et al. (2012). Right: Spreading factor measured for different liquids and impact velocity, traced following eq. 6. The dashed line represents the fit based on Padé approximant according to the asymptotic limits $\lim _{P \ll 1} f_{c}(P) \propto P^{1 / 2}$ and $\lim _{P \gg 1} f_{c}(P) \sim$ Cste, taken from Laan et al. (2014).

the spreading there $\left(\beta \propto W e^{1 / 2}\right)$ rather than the alternative one $\left(\beta \propto W e^{1 / 4}\right)$, as shown on Figure 5 b) where experiments with different liquids show a good collapse for the spreading factor according to equation 6 . Indeed, the later law would have suggested another impact parameter $P^{\prime}=W e \cdot R e^{-4 / 5}$ for which the collapse of the results is clearly less good (Eggers et al. (2010); Laan et al. (2014); Lastakowski et al. (2014)).

\subsection{Impact on a small target}

Impacts onto small circular targets, the size of the drop itself, free the spreading lamella from the viscous no-slip boundary condition at the solid substrate, thereby creating conditions closer to the above inviscid theory. This has been done in experiments by Rozhkov et al. (2010) and Villermaux \& Bossa (2011) focusing on the puncturing of the lamellar and fragmentation of its edge. Bakshi et al. (2007) studied impacts on small spherical targets, varying the substrate curvature. Most recently, Vernay et al. (2015) have measured the thickness of the free-standing sheet using fluorescence.

\section{SPLASHING: PROMPT VS CORONA SPLASH}

\subsection{Splashing threshold}

As the impact velocity $V$ is increased, eventually the drop will splash, i.e. break up and eject smaller pieces. Classically, the splashing threshold was characterized by the so-called splashing parameter proposed by Stow \& Hadfield (1981) and Mundo et al. (1995), which incorporated the inertia, viscous stress and surface tension, in the form

$$
K=W e \sqrt{R e} .
$$


For impacts at $K$ exceeding $~ 3000$ one can expect a splash. Many variants of the above powerlaws exist in the literature, see review in Moreira et al. (2010) and Marengo et al. (2011). Motivated by the early imaging of Rioboo et al. (2001), the nature of the splash has been split into two categories, prompt vs corona splash, shown in Figures 1 d) and e) respectively. Prompt splash releases droplets directly from the breakup of the tip of the advancing lamella, whereas in the corona splash the intact lamella rises away from the substrate forming a bowl-like structure, which subsequently breaks up into fine droplets (Figure 1e). Much effort has been devoted to finding the critical values of $K$ for the various impact conditions (Vander Wal et al. (2006); Roisman et al. (2015), etc).

\subsection{Influence of the surrounding gas}

However, the above formulation was proven to be incomplete by the unexpected discovery of $\mathrm{Xu}$, Zhang and Nagel (2005) that reducing the air pressure, while keeping other parameters unchanged, could suppress the splashing. This seminal discovery has triggered a renewed decade-long search for the underlying physics, in particular pinning down the role of the air and the surface roughness. As seen below, many proposals have appeared, but consensus has yet to emerge.

The interplay between surface roughness and gas pressure complicates the interpretation of the two splashing types. Xu et al. (2007) devised an ingenious way to study the size distribution of the ejected droplets, by simply surrounding the impact with a circular sheet of paper. The resulting splatters show different signatures for the two splashing types, with a thin horizontal line of spots for the prompt splash and a more vertically spread random distribution for the corona-splash. However, this technique only captured forward-moving droplets and was limited to droplets larger than $100 \mu \mathrm{m}$. Direct imaging of the splashed droplets (Thoroddsen et al. (2012)) in the prompt splash regime showed the earliest droplets are the smallest and emerge at the highest velocities, with early 5 $\mu \mathrm{m}$ droplets emerging at close to $90 \mathrm{~m} / \mathrm{s}$ or $10^{4}$ times their terminal velocity. They are therefore rapidly decelerated by air-drag and can easily become airborne. These observed droplet sizes support viscous growth of the thickness of the early lamella.

$\mathrm{Xu}$ et al. (2007) proposed that prompt splash is produced by surface roughness whereas the corona-splash by the air-drag at the front of the lamella. This cannot be the whole story, as prompt micro-splashing is observed by Thoroddsen et al. (2012) for impact on a smooth glass surface. More recently, Latka et al. (2012) have proposed that perhaps a single mechanism is at play, simply appearing at different spreading locations. They remove the influence of the corona-splash by conducting the experiments in low-pressure helium atmosphere, showing clearly that random surface roughness can reduce splashing by reducing the levitated film at the edge of the expanding lamella.

Stevens et al. (2014) has found empirical scaling for the splashing boundary on a smooth surface, using low-viscosity liquids, over a range of gas pressures. The scaling highlights the importance of the mean-free-path of the gas molecules.

Handful of studies have looked at splashing on inclined surfaces (Stow \& Hadfield (1981)), or rapidly translating surfaces. Chou et al. (2009) showed strong asymmetry and splashing even in the low $W e$ deposition regime, when the impact angle to the vertical exceeds $85^{\circ}$. Bird et al. (2009) additionally showed that the corona-splash can be suppressed on the lamellar stretching side, for a very large translational velocity of the substrate.

Supplemental Video: Prompt splashing of high-speed microscopic droplets 

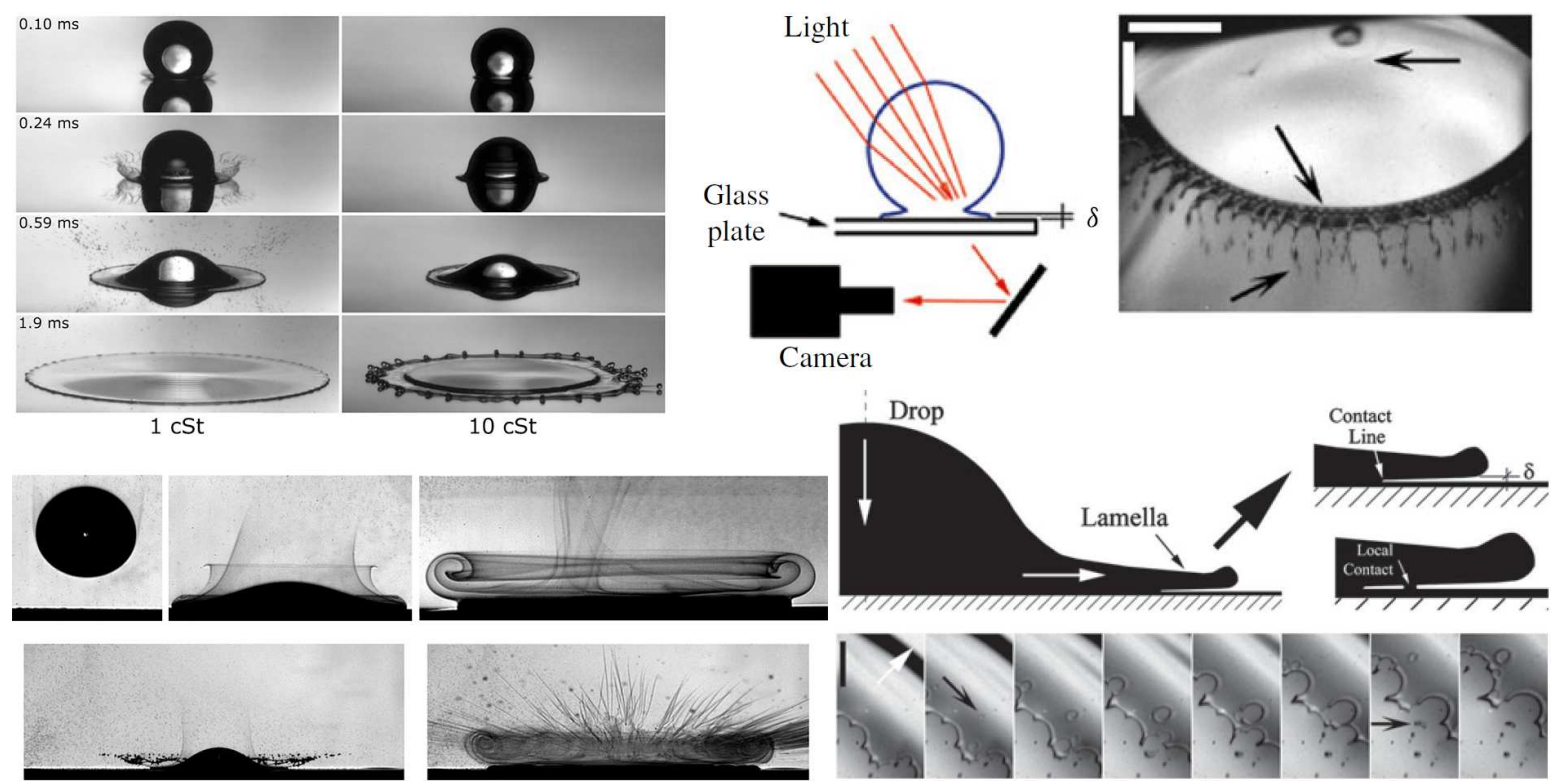

Figure 6

Splashing for different viscosities. (a) Comparison splashing of a low- and high-viscosity liquid: corona splash (left) and levitated lamella (right) from Driscoll et al. (2010). (b) Splashing occurs as soon as the lamella appears from the outer wetted region, with azimuthal pattern in the cusp, from Thoroddsen et al. (2012). (c) Visualizing the air-flow, using refractive index variations, from Bischofberger et al. (2013). (d) Entrapment of bubbles under the contact line, by localized contacts, from Thoroddsen et al. (2010). See supplementary videos.

Supplemental Video: Air entrapment under the advancing levitated lamella

\subsection{Levitated lamella}

Drop viscosity dramatically changes the splashing dynamics. For more viscous liquids the lamella lifts away from the substrate (Driscoll et al. (2010); Schroll et al. (2010)) and starts gliding on a thin sheet of air (Figure 6 a). The forces responsible for the levitation of the sheet, must arise from the dynamics around the rapidly moving contact line. Lubrication in the air under the sheet requires large advancing contact angle, whereas suction in the air-flow over the top is an inertial process. Bischofberger et al. (2013) have introduced glycerin vapor into the air, forming spectacular Schlieren images (Figure 6 c) to identify vortices forming above the leading edge of the lamella.

Thoroddsen et al. (2010) showed that this levitated lamella can become unstable and touch the solid surface ahead of the contact line, thereby not only entrapping a myriad of air-bubbles when these localized contacts meet the expanding contact line (Figure 6 d), but also rupturing the levitated lamella, producing a powerful capillary driven splash. This bubble entrapment was studied in more detail by Driscoll et al. (2010) and Palacios et al. (2012) who observed multiple rings of micro-bubbles. The earliest breakup of the lamellar edge, may be assisted by capillary instability in the cusp in the neck where the lamella connects to the drop (Figure $\mathbf{6 b}$ from Thoroddsen et al. (2012)), or by sawtooth instability at the contact line (Rein and Delplanque (2008)).

Stevens et al. (2014) propose that the delayed emergence of the thinner levitated jet from the tip of the lamella, is a generic mechanism, occurring even for low-viscosity impacts. They quantify this time delay as a function of viscosity and air pressure. For the prompt 

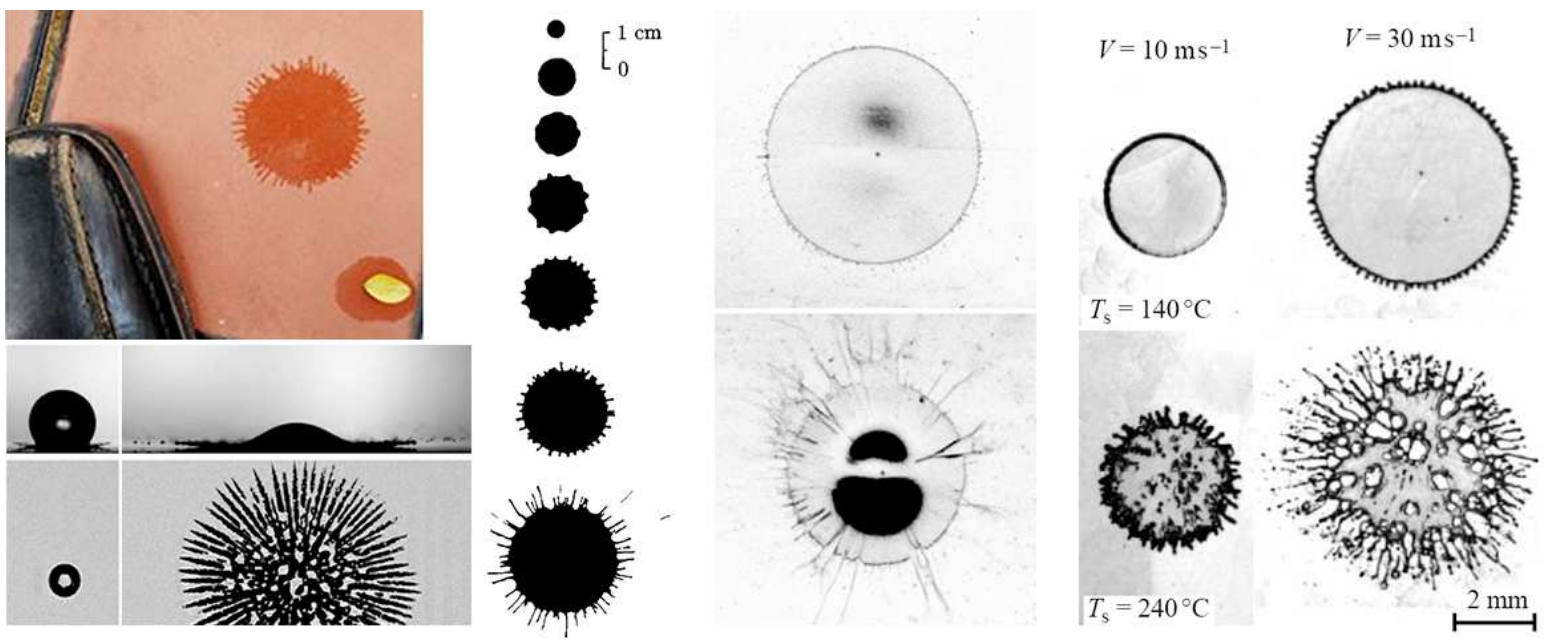

Figure 7

Splatter patterns. (a) Change in numbers and shape of fingering of an ink-blot on paper, when the impact height is increased, from Marmanis \& Thoroddsen (1996). (b) Edge splashing for very high impact velocities of 30 and $40 \mathrm{~m} / \mathrm{s}$, modified from Mehdizadeh et al. (2004). (c) Drop smacked by a solid plate moving at up to $30 \mathrm{~m} / \mathrm{s}$, showing the effect of surface superheat temperature, from Mehdizadeh \& Chandra (2006). (c) Drop smacked by a solid plate moving at up to $30 \mathrm{~m} / \mathrm{s}$, (d) Fingering of vapor channels for a boiling drop on heated surface, from Khavari et al. (2015).

splash the first appearance of the lamella is thereby emerging as a fundamental quantity, followed by the separation of its tip from the solid surface. However, immediately following the first wetting contact, the emergence of the lamella is controlled by the geometry of the drop and it can splash instantaneously for low viscosities, see for example Thoroddsen et al. (2012) who showed the droplet emerge immediately at a local tangential velocity to the lamellar tip motion. This was earlier studied by Mongruel et al. (2009) using multiple-strobe imaging.

\subsection{Recent theories}

Riboux and Gordillo (2014) have formulated a new splashing theory incorporating in part similar ideas for impact on a smooth partially wetting surface. They scaled the radial growth of the normalized wetted area as $r=\sqrt{3 t}$, with fluid elements ejected at velocity $v_{r}=\sqrt{3 / t}$. They propose that the lift-off of the lamella has two contributions, i.e. the lubrication force of the air upstream of the contact line (arising a priori for dynamic contact angle $>90^{\circ}$ ) and the suction force due to the flow over the edge (due to Bernoulli inviscid mechanism there). The lubrication part depends on contact angle and the mean-free path of the gas molecules, as already suggested in theoretical models involving non-continuum gas correction (Duchemin \& Josserand (2012); Mandre \& Brenner (2012)). Balancing the rising velocity of the tip of the ejecta to the capillary retraction Taylor-Culick velocity, gives a splashing threshold that compares well with extensive data from Palacios et al. (2013), as well as the reduced pressure data from Xu et al. (2005), but does not include influence of surface wettability or roughness.

Liu et al. (2015) show that a strategically placed ring of $75 \mu \mathrm{m}$ through-holes in the substrate can suppress the splashing, while closed pits do not. This suggests one needs 
to drain the air-layer from under the outer edge to stabilize it. They propose a KelvinHelmholtz instability at the interface between the thin air-layer and the bottom of the drop, as being responsible for the splashing, but the work lacks direct imaging of the proposed instability. Lembach et al. (2010) have also shown higher value for the splashing parameter for impacts onto porous substrates. On the other hand, splash can be triggered by an isolated protrusion, as shown by Josserand et al. (2005) or pit by de Jong et al. (2015). Kim et al. (2014) tested impacts on various closed-pit morphologies, also invoking K.-H. instability to explain lower critical values of the splashing parameter for larger pit areas.

Therefore, one can conclude that including the gas pressure in the splashing threshold must give rise to different scaling laws, as this effect is absent in the conventional splash parameter (eq. 7). In particular, varying the ambient gas pressure leads to a threshold such that the splashing is apparently enhanced by the gas viscosity Stevens et al. (2014); Stevens (2014) suggesting that an overall criterion including all the parameters is still missing. This is also the conclusion of the recent work of some of the authors of eq. 7, i.e. by Roisman et al. (2015). In particular, one should notice that incompressible lubrication equation for the gas cannot be enough to model the gas influence since it would involve the Stokes number only, that is independent of the gas pressure because of the Maxwell law (only the dynamical viscosity of the gas enters in the Stokes number). Thus, additional physical mechanisms, such as gas compressibility, inertia or non-continuum effects have to be considered.

Finally, the above studies highlight also the difficulty in distinguishing between prompt and corona splash, as exemplified by Riboux and Gordillo (2014) who show that the separated lamella can stabilize by reattaching to the substrate. In fact, the splashing threshold based on the splashing parameter $K$ (eq. 7) has been established without discriminating between prompt and corona splash so that an up-to date parametric study separating these two dynamics is needed.

\subsection{Fingering}

The splat left behind after the impact has a familiar fingering pattern, see Figure 7 . The early work of Allen (1975) attributed the fingers to Rayleigh-Taylor instability of the decelerating edge of the lamella, as suggested by recent linear stability analysis of a liquid rim (Agbaglah et al. (2013); Roisman et al. (2006)). However, clear fingering instability has been observed from the very start of the lamellar formation by Thoroddsen \& Sakakibara (1998), who also showed that fingers can split and merge during the spreading. Marmanis \& Thoroddsen (1996) dropped colored liquids onto thick cotton paper, showing that the number of fingers $N$ scales with a modified impact Reynolds number $N \propto\left(R e_{D}^{1 / 2} W e^{1 / 4}\right)^{3 / 4}$. Aziz \& Chandra (2000) proposed a different formula $N=R e^{1 / 4} W e^{1 / 2} / \sqrt{48}$ for molten droplets. Mehdizadeh et al. (2004) extended these measurements to much higher impact velocities $(\sim 50 \mathrm{~m} / \mathrm{s})$ using a surface moving on a fly-wheel, which whacks the drop in flight. They show reasonable scaling with Weber number $N=1.14 W e^{1 / 2}$, ignoring liquid viscosity. In the robust splashing regime, it becomes challenging to determine the number of fingers, as is clear in the snapshots in Figure 7(c). Same technique is used by Fassmann et al. (2013) to study sizes of splashed droplets. Even higher impact velocities $(\sim 100 \mathrm{~m} / \mathrm{s})$ of microdrops have been achieved by Visser et al. (2012), by exploiting laser-produced jetting (Thoroddsen et al. (2009)). Impacts at huge Re have been studied, by using larger 

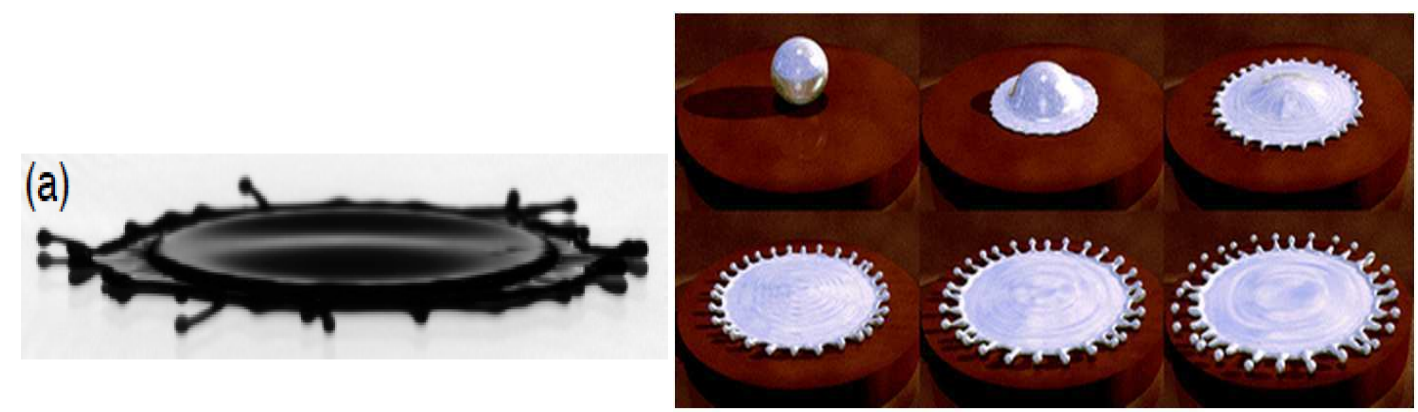

Figure 8

Fingers and droplet breakup observed in the case of liquid film skating of the solid surface, taken from Driscoll \& Nagel (2011). Fingering edge breakup obtained by direct numerical simulation, taken from Yokoi (2011).

liquid masses released from punctured balloons, but unavoidable external disturbances can obscure the impact-induced fingering (Yoon et al. (2007)).

Blood-splatter analysis can be instrumental in forensic sciences, see Hulse-Smith et al. (2005) and Laan et al. (2014). The combination of diameter and number of fingers of the dried spatter, can help pin down the droplet size and trajectory, see Attinger et al. (2013).

The splashing pattern itself depends obviously on the surface properties. At first, the wettability of the substrate is crucial for the splashing and breakup of the edge. The larger the contact angle the easier the splashing Yokoi (2011) (Figure 8). While the corona splash exhibits a typical S-shape ejecting small droplets, the skating thin film leads to the formation of fingers as shown on Figure 8.

Moreover, textured surface can also enhanced splashing while large bubble can be entrapped beneath the impacted drop Xu et al. (2007).

\section{THE EFFECTS OF SUBSTRATE PROPERTIES}

So far we have focused on impacts onto flat dry surfaces. Allowing modification of the substrate opens up uncountable variants. The surface can be porous or compliant (Pepper et al. (2008)); One can add patterned roughness elements, penetrating holes, closed pits, or spatially varying wettability. Such modifications are a particularly active area of study, due to a myriad of potential applications, from self-cleaning surfaces to enhanced heat transfer during spray cooling or anti-icing of airplane wings. This effort is being helped by the rapid development of new micro- and nano-fabrication techniques. Recent mushroomshaped double-reentrant superomniphobic surfaces show bouncing of fully wettable liquids, like hexadecane (Tuteja et al. (2008)) and even perfluorohexane (Liu \& Kim (2014)).

Motivated by the lotus leaf, superhydrophobic surfaces (i.e. hydrophobic and microstructured) have been engineered using various pillar arrangements, to make an impacting fakir drop bounce with restitution coefficient as high as 0.9 (Richard and Quéré (2000)). The early studies of Reyssat et al. (2006) and Bartolo et al. (2006) systematically varied the pillar height $h$ and spacing $\ell$, to find the critical impact velocity $V^{*}$ between the drop fully bouncing or partly wetting the surface, or in other words transitions from full to partial repellency. This transition occurs when the impact energy is sufficient to stretch the curved 


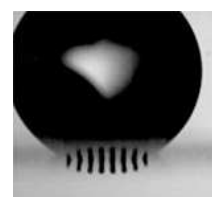

(a)
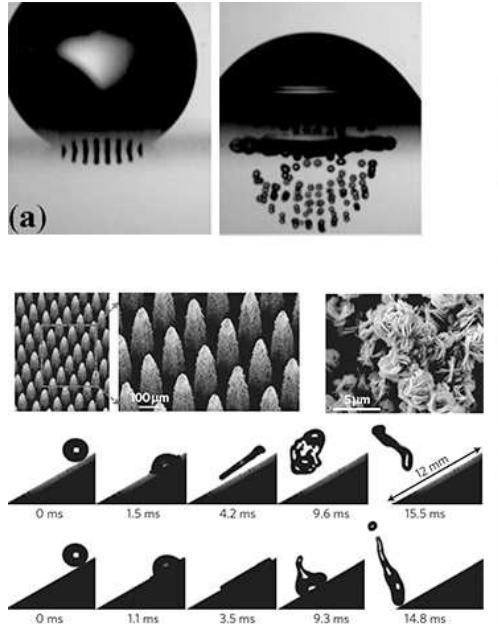

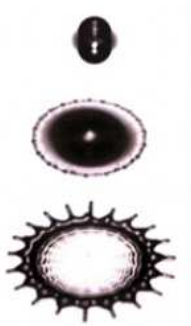

$0 \mathrm{~ms}$

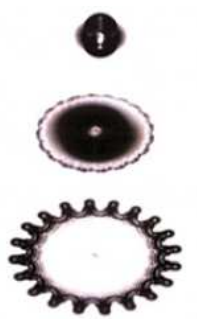

$0 \mathrm{~ms}$

$1.2 \mathrm{~ms}$

$1.2 \mathrm{~ms}$

$8.3 \mathrm{~ms}$

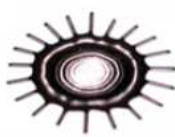

$13.0 \mathrm{~ms}$

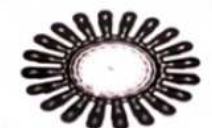

$4.8 \mathrm{~ms}$

$10.5 \mathrm{~m}$

final

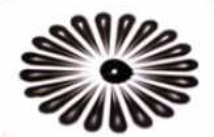

final

Figure 9

Shaping the splatter pattern. (a) Drop impacting on a regular grating ejecting smaller droplets, from Brunet et al. (2009). (b) Pancake rebound from superhydrophobic pillared surface, from Liu et al. (2014). (c) Impacts onto radial patterns. on left the radial lines are hydrophilic, whereas on right they are hydrophobic, modified from Lee et al. (2010).

free meniscus between the pillars until they touch the substrate, giving

$$
V^{*}=\sqrt{\sigma h / \rho \ell^{2}} .
$$

However, for even the most repellent surfaces at sufficiently high impact velocities the spreading edge of the lamella will break up and only part of the drop can rebound. van der Veen et al. (2014) used color interferometry to measure the shape of the meniscus between such pillars. Most recently, Antonini et al. (2014) applied X-rays to directly image the meniscus, to pin down this wetting transition. Recent mushroom-shaped double-reentrant superomniphobic surfaces show bouncing of fully wettable liquids, like hexadecane (Tuteja et al. (2008)) and even perfluorohexane (Liu \& Kim (2014)).

Richard et al. (2002) showed that the contact time of a drop impacting a smooth hydrophobic surface, is almost constant independent of the impact velocity, but grows linearly with drop size. Bird et al. (2013) showed that this time can be reduced by a cleverly constructed patterning of a superhydrophobic surface, which break the drop into smaller pieces. They suggest some leaves and butterfly wings have developed such patterns. Moevius et al. (2014) demonstrated what they call pancake rebound shown in Figure 4(b). This occurs when the impacting drop spreads along the texture, but subsequently rebounds away from it before it can retract, thereby retaining the flattened shape when the liquid leaves the surface. This has the possible advantage of reducing further the contact time of the drop with the substrate, which can be important in certain applications, such as anti-icing coatings. Coatings are also used to reduce bug-splatter remnants on wind-shields and airplane wings, where impact are usually at an angle (Yeong et al. (2014)).

The next level of surface complexity, involves modifications to promote directional rebounding, splitting the liquid into patterns or segmenting it onto wettable strips etc. Lee 
et al. (2010) studied impacts onto a wettability-patterned surface, consisting of hydrophobized radial spikes, emanating from the center of the impact location (Figure 9(c)). They successfully formed fine radial fingers at wavelengths different from the natural instability. Surprisingly, regular liquid patterns can be formed for both hydrophilic as well as hydrophobic line patterns, with the liquid resting on or in-between the patterns respectively. Reyssat et al. (2009) showed that variations of the post-spacing along the surface, can move the drops sideways. The impacting drops can be formed into wetting patterns, or redirecting the rebound (Schutzius et al. (2014)).

Solid substrates can be porous, or have isolated holes. Lorenceau \& Quéré (2003) impacted a drop on a plate with a hole, identifying critical $W e$ as function of $R e$, where some of the liquid is ejected through the hole. Brunet et al. (2009) impacted a drop onto a regular micro-grid, with holes in the form of truncated pyramides. The impact pushes through regular micro-droplets of sizes similar to the individual hole size (Figure 9a). They showed larger critical $W e$ if they turn over the plate to form a reentrant surface structure. Similarly, Sahu et al. (2015) used porous mats of nano-fibers, which have applications in heat exchangers. They see fine jets emerging through the bottom of the mat, at about 3 times faster than the drop impact velocity.

\subsection{Phase-change during the impact:}

For certain applications, it is desired that the drop go through a phase change during the impact. This can be solidification of a molten drop in soldering, or boiling of a drop during fuel-spay/wall interactions (Moreira et al. (2010)) and in extreme spray-cooling of electronic devices. Solidification is fundamental during inkjet soldering of electronics or fabrication of displays. Bhola \& Chandra (1999) studied solidification of paraffin wax, identifying the important parameters controlling the process. Aziz \& Chandra (2000) studied the solidified and splashing of molten metal droplets, defining a solidification parameter, characterizing when solidification will not affect the spreading.

Spray cooling can be most effective when it extracts heat into energy of vaporization of the spray droplets. Leidenfrost effects (Quéré (2013)) are thereby important, as they reduce heat transfer and enhance bouncing away from the substrate (Ko \& Chung (1996)). Biance et al. (2006) show Leidenfrost bounces with restitution coefficients exceeding unity, thereby extracting energy from the vaporization. Antonini et al. (2013) show rebound due to sublimation of a dry-ice substrate.

Moita \& Moreira (2007) studied oils and petrochemicals fuels, showing jetting in the nucleate boiling regime. Breakup of the Leidenfrost layer under the drop has been studied by Tran et al. (2012) using interferometry. They identified explosive vertical jetting through the spreading lamella, characterized the splashing for heated surfaces, encompassing the Leidenfrost regime.

Fingering of radial vapor lines during impact boiling was also observed in TIR images under the drop, at temperatures slightly under Leidenfrost (Khavari et al. (2015)).

\subsection{Splashing of composite drops}

Liquid suspensions and emulsions are ubiquitous in chemical processing and often form droplets. The impact of such droplets is thereby of interest, for example in spray cooling, lubrication and combustion. Prunet-Foch et al. (1998) studied coolant/lubricant oil-water emulsions, sprayed on cold-rolling mills used in steel strip manufacturing. The impacts 


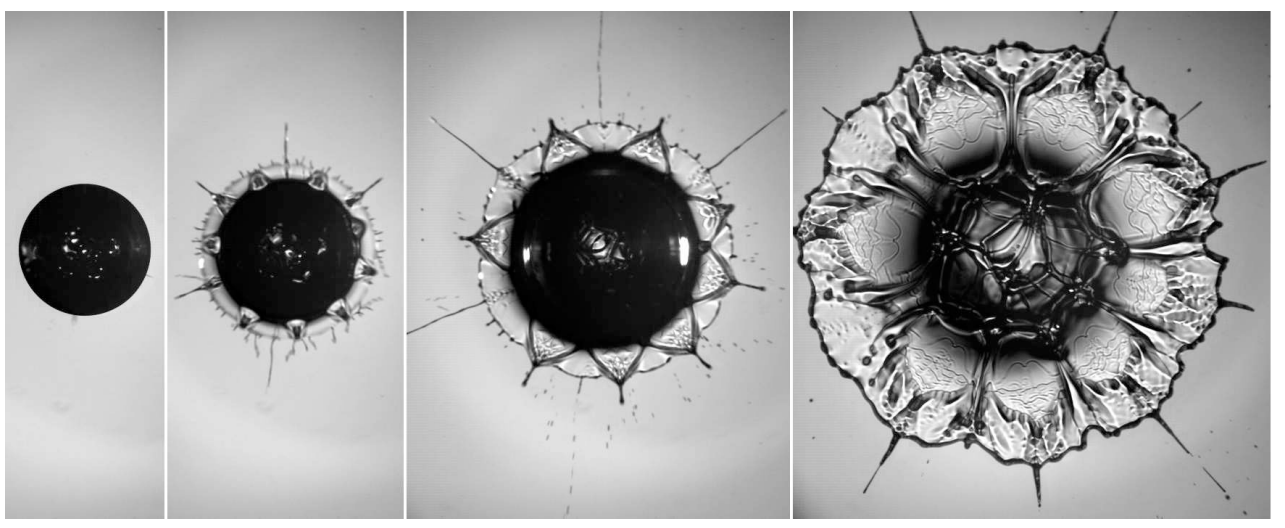

Figure 10

(a) The impact of a compound drop, outer drop $2 \mathrm{cP}$ and 20 inner PP1 droplets. for impact velocity $V \simeq 4 \mathrm{~m} / \mathrm{s}$, drop $D=5$ ?? $\mathrm{mm}$. Frames are shown at $t=0,0.08,0.25 \& 0.8 \mathrm{~ms}$ after first contact (courtesy Jiaming Zhang \& Erqiang Li). Note the repeatability of the fine structure.

showed fine jetting, attributed to oil droplets being ejected out of the free surface. Figure 10 shows the impact of a drop containing large heavier internal perfluorohexane droplets, which settle near the bottom of the main drop. This forms isolated jetting as the impact pressure field is focused around the internal smaller droplets, showing the importance of the number and location of the inner droplets. Counterjets are observed during the impact of hollow drops by Gulyaev \& Solonenko (2013).

Impact of dense suspensions of small solid particles have been imaged by Marston et al. (2013), showing grains ejected at twice the impact velocity of the granular drop. Peters et al. (2013) demonstrated that one should use a particle-based Weber number to predict the onset of splashing. Interestingly, for bimodal particles the smaller ones are more readily ejected. Splashing of non-Newtonian liquids is not well studied so far (Guemas et al. (2012)).

\section{OPEN QUESTIONS AND FUTURE DIRECTIONS}

Naturally, research into the complex phenomenon of drop impact, focused first on the simplest configurations, but has now shifted to fully attack the complexity of surface structure, complex-liquid drops etc. Here are some of the issues which we believe need to be tackled.

- Following the seminal discovery of Xu et al. (2005) that splashing is suppressed by reduced air pressure, many groups have tried to find the underlying mechanism. Numerous proposals have recently been put forth, some of which could be correct. Main focus is now on the levitation of the tip of the lamella, as it travels along the substrate (Latka et al. (2012); Stevens et al. (2014); Riboux and Gordillo (2014); Liu et al. (2015)). Improved imaging should pinpoint the most promising explanations for the different impact conditions, to show whether a single unified splashing theory exists.

- One uncertainty in this regards is the fuzzy definition of the splashing boundary, especially in the presence of surface roughness. Random roughness will inherently 
give random results, making it non-trivial to determine the splashing limit. See for example the large overlap of the splashing and deposition regimes observed in Roisman et al. (2015). High-speed micro-splashing may also have been overlooked by early researchers (Thoroddsen et al. (2012)). Furthermore, for drops larger than the capillary length, they are easily deformed from spherical shape and air-drag in free-fall can flatten them. This invariable affects impact outcomes (Thoroddsen et al. (2005); Mishra et al. (2011); Liu et al. (2013)), but was not characterized in many earlier studies.

- Finding and predicting the splashing threshold is a worthwhile quest in and of itself. However, of greater practical importance will be to fully characterize the resulting splash. The size and number of the finest droplets is for example important for generation of aerosols. Trajectories of droplets are important for uniformity of coatings, contamination, or rain erosion.

- Most experiments only study drop silhouettes and numerics assume axisymmetry. Perhaps some instabilities reside in the flow-field inside the drop, as has recently been shown numerically by Thoraval et al. (2012) for the drop-pool ejecta sheet. This poses fresh experimental challenges, which may be overcome in the near future.

- Overwhelming majority of impact studies are far away from supersonic conditions (Haller et al. (2002); Lesser \& Field (1983)). However, such impacts can arise in applications, like sprays from high-pressure fuel injectors. Shock waves and the water-hammer pressure, give rise to new dynamics. Direct measurements of the very large local forces involved might be possible with microscopic sensors. Overall forces can be measured using flexible glass substrates (Soto et al. (2014)).

- Practically most impacts are oblique to the surface. This configuration deserves more attention.

- Repeated drop impacts quickly wet the surface and transform the dynamics to impacts onto liquid films, a topic not covered herein, but even very thin films can have strong effect on impact outcomes.

With accelerating improvements in both high-speed sensor technology and computational power, we expect the coming decade to provide even more breakthroughs in the study of drop impact, than have already occurred in the last decade since the review of Yarin (2006).

\section{Acknowledgements}

It is our pleasure to thank all our collaborators on this fascinating problem of drop impact and in particular Jun Sakakibara, Erqiang Li, Ivan Vakarelski, Marie-Jean Thoraval, Jeremy Marston, Gilou Agbaglah, Zhen Jian, Stéphane Popinet, Pascal Ray, Stéphane Zaleski and Jiaming Zhang for their support through the years. STT especially thanks Haralambos Marmanis for introducing him to the subject. Finally, we want to thank all our colleagues contacted for the use of their images in this review.

\section{LITERATURE CITED}

Agbaglah G, Delaux S, Fuster D, Hoepffner J, Josserand C, Popinet S, Ray P, Scardovelli R, Zaleski S. 2011. Parallel simulation of multiphase flows using octree adaptivity and the volume-of-fluid method. C. R. Mecanique 339:194-207 
Agbaglah G, Josserand C, Zaleski S. 2013. Longitudinal instability of a liquid rim. Phys. Fluids, 25:022103

Allen RF. 1975. The role of surface tension in splashing. J. Colloid Interface Sci. 51:350-351

Antonini C, Bernagozzi I, Jung S, Poulikakos D, Marengo M. 2013. Water Drops Dancing on Ice: How Sublimation Leads to Drop Rebound. Phys. Rev. Lett. 111:014501

Antonini C, Lee JB, Maitra T, Irvine S, Derome D, Tiwari MK, Carmeliet J, Poulikakos D. 2014. Unraveling wetting transition through surface textures with X-rays: Liquid meniscus penetration phenomena. Sci. Rep. 4:4055

Antkowiak A, Audoly B, Josserand C, Neukirch S, Rivetti M. 2011. Instant fabrication and selection of folded structures using drop impact Proc. Natl. Acad. Sci. U.S.A. 108:10400-4

Attinger D, Moore C, Donalson A, Jafari A, Stone HA. 2013. Fluid dynamics topics in bloodstain pattern analysis: Comparative review and research opportunities. Forensic Sci. Intern. 231:375396

Aziz SD, Chandra S. 2000. Impact, recoil and splashing of molten metal droplets, Int. J. Heat, Mass Trans. 43:2841-2857

Bakshi S, Roisman IV, Tropea C. 2007. Investigations on the impact of a drop onto a small spherical target. Phys. Fluids, 19:032102

Bartolo D, Bouamrirene F, Verneuil E, Buguin A, Silberzan P, Moulinet S. 2009. Bouncing or sticky droplets: Impalement transitions on superhydrophobic micropatterned surfaces. Europhys. Lett. 74:299-305

Bartolo D, Josserand C, Bonn D. 2005. Retraction dynamics of aqueous drops upon impact on nonwetting surfaces, J. Fluid Mech. 545:329-338

Bartolo D, Josserand C, Bonn D. 2006. Singular jets and bubbles in drop impact, Phys. Rev. Lett. 96:124501

Bayer IS, Megaridis CM. 2006. Contact angle dynamics in droplets impacting on flat surfaces with different wetting characteristics, J. Fluid Mech. 558:415-449

Bhola R, Chandra S. 1999. Parameters controlling solidification of molten wax droplets falling on a solid surface. J. Mat. Sci. 34:4883-4894

Biance A-L, Chevy F, Clanet C, Lagubeau G, Quéré. 2006. On the elasticity of an inertial liquid shock. J. Fluid Mech. 554:47-66

Bird JC, Tsai S, Scott SH, Stone HA. 2009. Inclined to splash: triggering and inhibiting a splash with tangential velocity. New J. Physics 11:063017

Bird JC, Dhiman R, Kwon H-M, Varanasi KK. 2013. Reducing the contact time of a bouncing drop. Nature 503:385-388

Bischofberger I, Mauser KW, Nagel SR. 2013. Seeing the invisible-Air vortices around a splashing drop. Phys. Fluids 25:091110

Bouwhuis W, van der Veen RCA, Tran T, Keiji DL, Winkels KG, et al. 2012. Maximal air bubble entrainment at liquid-drop impact. Phys. Rev. Lett. 109:264501

Brunet P, Lapierre F, Zoueshtiagh F, Thomy V, Merlen A. 2009. To grate a liquid into tiny droplets by its impact on a hydrophobic microgrid. App. Phys. Lett. 95:254102

Chandra S, Avedisian CT. 1991. On the collision of a droplet with a solid surface. Proc. R. Soc. Lond. A, 432:13-41

Chou F-C, Zen T-S, Lee K-W. 2009. An experimental study of a water droplet impacting on a rotating wafer. Atom. Spray, 19:905-16

Clanet C, Béguin C, Richard D, Quéré. 2004. Maximal deformation of an impacting drop. J. Fluid Mech., 517:199-208

Deng X, Mammen L, Butt H-J, Vollmer D. 2012. Candle soot as a template for a transparent robust superamphiphobic coating, Science, 107:67-70

Driscoll MM, Nagel SR. 2011. Ultrafast interference imaging of air in splashing dynamics. Phys. Rev. Lett. 107:154502

Driscoll MM, Stevens CS, Nagel SR. 2010. Thin film formation during splashing of viscous liquids. 
Phys. Rev. E 83:036302

Duchemin L and Josserand C. 2011. Curvature singularity and film-skating during drop impact Phys. Fluids, 23:091701

Duchemin L and Josserand C. 2012. Rarefied gas correction for the bubble entrapment singularity in drop impacts, C.R. Mecanique, 340:797-803

Eggers J, Fontelos M, Josserand C, Zaleski S. 2010. Drop dynamics after impact on a solid wall: Theory and simulations, Phys. Fluids, 22:062101

Fassmann BW, Bansmer SE, Moeller TJ, Radespiel R, Hartmann M. 2013. High velocity impingement of single droplets on a dry smooth surface, Exp. Fluids, 54:1516

Fedorchenko AI, Wang A-B, Wang Y-H. 2005. Effect of capillary and viscous forces on spreading of a liquid drop impinging on a solid surface Phys. Fluids, 17:093104

Guemas M, Marin AG, Lohse D. 2009. Drop impact experiments of non-Newtonian liquids on micro-structured surfaces. Soft Matter, 8:10725

Gulyaev IP, Solonenko OP. 2013. Hollow droplets impacting onto a solid surface. Exp. Fluids 54, 1432.

Haller KK, Ventikos Y, Poulikakos D, Monkewitz P. 2002. Computational study of high-speed liquid droplet impact. J. Appl. Phys. 92:2821-28

Hendrix MHW, Bouwhuis W, van der Meer D, Lohse D, Snoeijer JH. 2015. Universal mechanism for air entraiment during liquid impact. manuscript.

Hicks PD, Ermanyuk EV, Gavrilov NV, Purvis R. 2012. Air trapping at impact of a rigid sphere onto a liquid. J. Fluid Mech. 695:310-20

Hicks PD, Purvis R. 2010. Air cushioning and bubble entrapment in three-dimensional droplet impacts. J. Fluid Mech. 649:135-63

Hicks PD and Purvis R. 2013. Liquid-solid impacts with compressible gas cushioning, J. Fluid Mech., 735:120-149

Huang Y-L, Wang M-J, Huang J-W, Lin S-Y. 2013. A study on the impact velocity and drop size for the occurrence of entrapped air bubbles - Water on parafilm, Exp. Thermal Fluid sci. 48:102-09

Hulse-Smith L, Mehdizadeh NZ, Chandra S. 2005. Deducing drop size and impact velocity from circular bloodstains, J. Forensic Sci. 50:54-63.

de Jong R, Enriquez OR, van der Meer D. 2015. Droplet impact near a millimetre-size hole: closed pit versus open-ended pore, Manuscript under review.

Josserand C, Lemoyne L, Troeger R, Zaleski S. 2005. Droplet impact on a dry surface: triggering the splash with a small obstacle, J. Fluid Mech. 524:47-56

Khavari M, Sun C, Lohse D, Tran T. 2015. Fingering patterns during droplet impact on heated surfaces, Soft Matter, DOI:10.1039/c4sm2878c

Kim H, Park U, Lee C, Kim H, Kim MH, Kim J. 2014. Drop splashing on a rough surface: How surface morphology affects splashing threshold, Appl. Phys. Lett. 104:161608

Klaseboer E, Chevaillier JP, Gourdon C, Masbernat O. 2000. Film drainage between colliding drops at constant approach velocity: experiments and modeling. J. Colloid Interface Sci. 229:274-85

Klaseboer E, Manica R, Chan DYC. 2014. Universal behavior of the initial stage of drop impact. Phys. Rev. Lett. 113:194501

Ko YS, Chung SH. 1996. An experiment on the breakup of impinging droplets on a hot surface. Exp. Fluids, 21:118-23

Kolinski JM, Rubinstein SM, Mandre S, Brenner MP, Weitz DA. 2012. Skating on a film of air: drops impacting on a surface. Phys. Rev. Lett. 108:074503

Kolinski JM, Mahadevan L, Rubinstein SM, 2014. Lift-Off Instability During the Impact of a Drop on a Solid Surface. Phys. Rev. Lett. 112:134501

Kolinski JM, Mahadevan L, Rubinstein SM. 2014. Drops can bounce from perfectly hydrophilic surfaces. Euro. Phys. Lett. 108:24001

Korobkin AA, Ellis AS, Smith FT. 2008. Trapping of air in impact between a body and shallow water. J. Fluid Mech. 611:365-94 
Kwon D, Huh H, Lee S. 2013. Wetting state and maximum spreading factor of microdroplets impacting on superhydrophobic textured surfaces with anisotropic arrays of pillars. Exp. Fluids $54: 1576$

Laan N, de Bruin KG, Bartolo D, Josserand C, Bonn D. 2014. Maximum diameter of impacting liquid droplets, Phys. Rev. Appl. 2:044018

Lagubeau G, Fontelos MA, Josserand C, Maurel A, Pagneux V, Petitjeans P. 2012. Spreading dynamcis of drop impacts. J. Fluid Mech. 713:50-60

Lastakowski H, Boyer F, Biance A-L, Pirat C, Ybert C. 2014. Bridging local to global dynamics of drop impact onto solid substrates. J. Fluid Mech. 747:103-18

Latka A, Strandburg-Peshkin A, Driscoll MM, Stevens CS and Nagel SR. 2012. Creation of prompt and thin-sheet splashing by varying surface roughness or increasing air pressure, Phys. Rev. Lett. 109:054501

Lee JS, Weon BM, Je JH, Fezzaa K. 2012. How does an air film evolve into a bubble during drop impact? Phys. Rev. Lett. 109:204501

Lee M, Chang YS, Kim H-Y. 2010. Drop impact on microwetting patterned surfaces. Phys. Fluids 22:072101

Lembach AN, Tan H-B, Roisman IV, Gambaryan-Roisman T, Zhang Y, Tropea C, Yarin AL. 2010. Drop impact, spreading, splashing, and penetration into electrospun nanofiber mats. Langmuir, 26:9516-23

Lesser M, Field JE. 1983. The impact of compressible liquids. Annu. Rev. Fluid Mech. 15:97122.

Li EQ, Thoroddsen ST. 2015. Time-resolved imaging of compressible air-disc under a drop impacting a solid surface (submitted for publication).

Liu Y, Moevius L, Xu X, Qian T, Yeomans JM, Wang Z. 2014. Pancake bouncing on superhydrophobic surfaces. Nat. Phys. 10:515-19

Liu Y, Tan P, Xu L. 2013 Compressible air entrapment in high-speed drop impacts on solid surfaces. J. Fluid Mech. 716:R9

Liu Y, Tan P, Xu L. 2015. KelvinHelmholtz instability in an ultrathin air film causes drop splashing on smooth surfaces. Pro. Nat. Acad. Sci. USA ??:????, www.pnas.org/cgi/doi/10.1073/pnas.1417718112

Liu TL, Kim CJ. 2014. Turning a surface superrepellent even to completely wetting liquids. Science, 346:1096-1100

Lorenceau E, Quéré D. 2003. Drop impacting a sieve. J. Colloid Interface Sci. 263:244-49

Maitra T, Tiwari MK, Antonin C, Schoch P, Jung S, EberleP, Poulikakos D. 2014. On the nanoengineering of superhydrophobic and impalement resistant surface textures below the freezing temperature Nano Lett. 14:172-82

Mandre S, Brenner MP. 2012. The mechanism of a splash on a dry solid surface, J. Fluid. Mech. 690:148-72

Mandre S, Mani M, Brenner MP. 2009. Precursors to splashing of liquid droplets on a solid surface. Phys. Rev. Lett. 102:134502

Mani M, Mandre S, Brenner MP. 2010. Events before droplet splashing on a solid surface. J. Fluid. Mech. 647:163-85

Marengo M, Antonini C, Roisman IV, Tropea C. 2011. Drop collisions with simple and complex surfaces. Curr. Opin. Colloid Interface Sci. 16:292-302

Marmanis H, Thoroddsen ST. 1996. Scaling of the fingering pattern of an impacting drop. Phys. Fluids 8:1344-46

Marston JO, Vakarelski IU, Thoroddsen ST. 2013. Bubble entrapment during sphere impact onto quiescent liquid surfaces. J. Fluid Mech., 680, 660-670.

Marston JO, Mansoor MM, Thoroddsen ST. 2013. Impact of granular drops. Phys. Rev. E 88:010201(R)

Mehdizadeh NZ, Chandra S, Mostaghimi J. 2004. Formation of fingers around the edges of a drop hitting a metal plate with high velocity. J. Fluid Mech. 510:353-373. 
Mehdizadeh NZ, Chandra S. 2006. Boiling during high-velocity impact of water droplets on a hot stainless steel surface. Proc. R. Soc. A, 462:311531

Minemawari H, Yamada T, Matsui H, Tsutsumi J, Haas S, Chiba R, Kumai R, Hasegawa T. 2011. Inkjet printing of single-crystal films Nature, 475:364-67

Mishra NK, Zhang Y, Ratner A. 2011. Effect of chamber pressure on spreading and splashing of liquid drops upon impact on a dry smooth stationary surface Exp. Fluids, 51:483-91

Moevius L, Liu Y, Wang Z, Yeomans JM. 2014. Pancake bouncing: Simulations and theory and experimental verification. Langmuir 30:13021-32

Moita AS, Moreira ALN. 2007. Drop impacts onto cold and heated rigid surfaces: morphological comparisons, disintegration limits and secondary atomization. Int. J. Heat Fluid Flow 28:73552

Mongruel A, Daru V, Feuillebois F and Tabakova SS. 2009. Early post-impact time dynamics of viscous drops onto a solid dry surface, Phys. Fluids, 21:032101 (2009).

Moreira ALN, Moita AS, Cossali E, Marengo M, Santini M. 2007. Secondary atomization of water and isooctane drops impinging on tilted heated surfaces. Exp. Fluids 43:297-313

Moreira ALN, Moita AS, Panao. 2010. Advances and challenges in explaining fuel spray impingement: How much of single droplet impact research is useful? Prog. Energy Comb. Sci. 36:554-80

Mundo C, Sommerfeld M, Tropea C. 1995. Droplet-wall collisions: experimental studies of the deformation and breakup process. Int. J. Multiphase Flow 21:151-73

Palacios J, Hernández J, Gómez P, Zanzi C, López J. 2012. On the impact of viscous drops onto dry smooth surfaces, Exp. Fluids, 52:1449-63

Palacios J, Hernandez J, Gomez P, Zanzi C and Lopez J. 2013. Experimental study of splashing patterns and the splashing/deposition threshold in drop impacts onto dry smooth solid surfaces, Exp. Thermal, Fluid Sci. 44:571-82

Pasandideh-Fard M, Qiao, YM, Chandra S, Mostaghimi J. 1996. Capillary effects during droplet impact on a solid surface, Phys. Fluids, 8:650-9

Pepper RE, Courbin L, Stone HA. 2008. Splashing on elastic membranes: The importance of earlytime dynamics. Phys. Fluids, 20:082103

Peters IR, Xu Q, Jaeger HM. 2013. Splashing onset in dense suspension droplets. Phys. Rev. Lett. 111:028301

Piroird K, Clanet C, Lorenceau E, Quéré D. 2009. Drops impacting inclined fibers. J. Colloid. Interface Sci. 334:70-74

Pittoni PG, Lin Y-C, Wang R-J, Yu T-S, Lin S-Y. 2015. Bubbles entrapment for drops impinging on polymer surfaces: The roughness effect. Exp. Therm. Fluid Sci. 62:183-91

Prunet-Foch, B and Legay, F and Vignes-Adler, M and Delmotte, C. 1998. Impacting emulsion drop on a steel plate: influence of the solid substrate. J. Colloid Interface Sci. 199:151-68

Quéré D. 2013. Leidenfrost dynamics. Annu. Rev. Fluid Mech. 45:197-215

Range K and Feuillebois F. 1998. Influence of surface roughness on liquid drop impact, J. Colloid Interface Sci. 203:16-30

Rein M, Delplanque J-P. 2008. The role of air entrainment on the outcome of drop impact on a solid surface. Acta Mech. 201:105-18

Rein M. 1993. Phenomena of liquid drop impact on solid and liquid surfaces, Fluid Dyn. Res. 12:61-93

Renardy Y, Popinet S, Duchemin L, Renardy M, Zaleski S, Josserand C, Drumright-Clarke MA, Richard D, Clanet C, Quéré D. 2003. Pyramidal and toroidal water drops after impact on a solid surface, J. Fluid Mech. 484:69-83

Reyssat M, Pepin A, Marty F, Chen Y, Quéré D. 2006. Bouncing transitions on microtextured materials. Europhys. Lett. 74:306-12

Reyssat M, Pardo F, Quéré D. 2009. Drops onto gradients of texture. Europhys. Lett. 87:36003

Riboux G and Gordillo JM, 2014. Experiments of drops impacting a smooth solid surface: A model of the critical impact speed for drop splashing, Phys. Rev. Lett. 113:024507

Richard D, Quéré D. 2000. Bouncing water drops. Europhys. Lett. 50:769-75 
Richard D, Clanet C, Quéré D. 2002. Contact time of a bouncing drop. Nature, 417:811

Rioboo R, Tropea C, Marengo M. 2001. Outcomes from a drop impact on solid surfaces. At. Sprays 11:155-65

Rioboo R, Marengo M, Tropea C. 2002. Time evolution of liquid drop impact onto solid, dry surfaces Exp. Fluids 33:112-124

Rioboo R, Adao MH, Voue M, De Coninck J. 2006. Experimental evidence of liquid drop break-up in complete wetting experiments. J. Mater. Sci. 41:5068-80

Roisman IV, Rioboo R, Tropea C. 2002. Normal impact of a liquid drop on a dry surface: model for spreading and receding. Proc. R. Soc. A 458:1411-30

Roisman IV, Horvat K, Tropea C. 2006. Spray impact: rim transverse instability initiating fingering and splash and description of a secondary spray. Phys. Fluids 18:102104

Roisman IV, Berberović E, Tropea C. 2009a. Inertia dominated drop collisions. I. On the universal flow in the lamella Phys. Fluids, 21:052103

Roisman IV. 2009b. Inertia dominated drop collisions. II. An analytical solution of the Navier-Stokes equations for a spreading viscous film. Phys. Fluids, 21:052104

Roisman IV, Lembach A, Tropea C. 2015. Drop splashing induced by target roughness and porosity: The size plays no role. Colloid Interface Sci. accepted manuscript

Rozhkov A, Brunet-Foch B, Vignes-Adler M. 2010. Impact of drops of surfactant solutions on small targets. Proc. R. Soc. A. 466:2897-2916

de Ruiter J, Oh JM, van den Ende D and Mugele F. 2012. Dynamics of collapse of air films in drop impact, Phys. Rev. Lett., 108:074505

de Ruiter J, van den Ende D, Mugele F. 2014. Air cushioning in droplet impact. II: Experimental characterization of the air film evolution, Phys. Fluids, 27:012105

de Ruiter J, Lagraauw R, van den Ende D, Mugele F. 2015 Wettability-independent bouncing on flat surfaces mediated by thin air films, Nat. Phys. 11:48-53

Sahu RP, Sett S, Yarin AL, Pourdeyhimi B. 2015. Impact of aqueous suspension drops onto nonwettable porous membranes: Hydrodynamic focusing and penetration of nanoparticles. Colloids Surfaces A 467:31-45

Scheller BL, Bousfield DW. 1995. Newtonian drop impact with a solid surface, AIChE J. 41:1357-67

Schroll RD, Josserand C, Zaleski S, Zhang WW. 2010. Impact of a viscous liquid drop, Phys. Rev. Lett. 104:034504

Shinoda K, Murakami H, Kuroda S, Oki S, Takehara K, Etoh TG. 2007. High-speed thermal imaging of yttria-stabilized zirconia droplet impinging on substrate in plasma spraying, Appl. Phys. Lett. 90:194103

Shinoda K, Raessi M, Mostaghimi J, Yoshida T, Murakami H. 2009. Effect of substrate concave pattern on splat formation of Yttria-stabilized Zirconia in atmospheric plasma spraying, J. Therm. Spray Tech. 18: 609-618

Schutzius TM, Graeber G, Elsarkawy M, Oreluk J, Megaridis CM. 2014. Morphing and vectoring impacting droplets by means of wettability-engineered surfaces, Sci. Rep. 4:7029

Smith FT, Li L, Wu GX. 2003. Air cushioning with a lubrication/inviscid balance. J. Fluid Mech. 482:291318

Soto D, De Larivière AB, Boutillon X., Clanet C, Quéré D. 2014. The force of impacting rain. Soft Matter 10:4929-34

Stevens CS, Latka A, Nagel SN. 2014. Comparison of splashing in high- and low-viscosity liquids. Phys. Rev. E, 89:063006

Stevens CS. 2014. Scaling of the splash threshold for low-viscosity fluids. Euro. Phys. Lett. 106:24001

Stow CD, Hadfield MG. 1981. An Experimental Investigation of Fluid Flow Resulting from the Impact of a Water Drop with an Unyielding Dry Surface. Proc. Royal Soc. London. A. Math. Phys. Sciences 373:419-41

Thoraval M-J, Takehara K, Etoh TG, Popinet S, Ray P, Josserand C, Zaleski S, Thoroddsen ST. 2012. Von Kármán vortex street within an impacting drop, Phys. Rev. Lett., 108, 264506 
Thoroddsen ST, Etoh TG, Takehara K, Ootsuka N, Hatsuki Y. 2005. The air-bubble entrapped under a drop impacting on a solid surface. J. Fluid Mech. 545:203-12

Thoroddsen S T, Etoh TG, Takehara K. 2008. High-speed imaging of drops and bubble. Ann. Rev. Fluid Mech. 40:257-85

Thoroddsen ST, Takehara K, Etoh TG, Ohl C.-D. 2009. Spray and microjets produced by focusing a laser pulse into a hemispheric drop, Phys. Fluids, 21:112101

Thoroddsen ST, Takehara K, Etoh TG. 2010. Bubble entrapment through topological change. Phys. Fluids 22:051701

Thoroddsen ST, Takehara K, Etoh TG. 2012. Micro-splashing by drop impacts. J. Fluid Mech. 706:560-70

Thoroddsen ST, Sakakibara J. 1998. Evolution of the fingering pattern of an impacting drop. Phys. Fluids 10:1359-74

Tran T, Staat HJJ, Prosperetti A, Sun C, Lohse D. 2012. Drop impact on superheated surfaces. Phys. Rev. Lett. 108:036101

Tsai PA, van der Veen RCA, van de Raa M, Lohse D. 2010. How micropatterns and air pressure affect splashing on surfaces. Langmuir 26:16090-95

Tuteja A, Choi W, Mabry JM, McKinley GH, Cohen RE. 2008. Robust omniphobic surfaces. PNAS 105:18200-05

Tsai P, Pacheco S, Pirat C, Lefferts L, Lohse D (2009) Drop impact upon micro- and nanostructured superhydrophobic surfaces. Langmuir, 25:1229398

Tsai PA, Hendrix MHW, Dijkstra RRM, Shui L, Lohse D. 2011. Microscopic structure influencing macroscopic splash at high Weber number. Soft Matter 7:11325-33

Ukiwe C, Kwok D. 2005. On the Maximum Spreading Diameter of Impacting Droplets on WellPrepared Solid Surfaces. Langmuir, 21:666-673

Vadillo D, Soucemarianadin A, Delattre C, Roux D. 2009. Dynamic contact angle effects onto the maximum drop impact spreading on solid surfaces. Phys. Fluids, 21:122002

Van Dam DB, Le Clerc C. 2004. Experimental study of the impact of an ink-jet printed droplet on a solid substrate. Phys. Fluids, 16:340314.

van der Veen RCA, Tran T, Lohse D, Sun C. 2012. Direct measurements of air layer profiles under impacting droplets using high-speed color interferometry. Phys. Rev. E 85:026315

van der Veen RCA, Hendrix MHW, Tran T, Sun C, Tsai PA, Lohse D. 2014. How microstructures affect air film dynamics prior to drop impact. Soft Matter, 10:3703

vander Wal RL, Berger GM, Mozes SD. 2006. The splash/non-splash boundary upon a dry surface and thin fluid film. Exp. Fluids, 40:53-59

Vernay C, Ramos L, Ligoure C. 2015. Free radially expanding liquid sheet in air: time- and spaceresolved measurement of the thickness field. J. Fluid Mech. 764:428-44

Villermaux E, Bossa B. 2011. Drop fragmentation on impact. J. Fluid Mech. 668:412-35

Visser CW, Tagawa Y, Sun C, Lohse D. 2012. Microdroplet impact at very high velocity. Soft Matter, 8:10732-37

Visser CW, Frommhold PE, Wildeman S, Mettin R, Lohse D, Sun C. 2015. Dynamics of high-speed micro-drop impact: numerical simulations and experiments at frame-to-frame times below 100 ns. Soft Matter, 11:1708-22

Weiss DA, Yarin AL. 1999. Single drop impact onto liquid films: neck distortion, jetting, tiny bubble entrainment, and crown formation. J. Fluid Mech. 385:229-54

Worthington AM. 1876. On the forms assumed by drops of liquids falling vertically on a horizontal plate. Proc. Roy. Soc. Lond. 25:261

Xu L, Barcos L, Nagel SR. 2007. Splashing of liquids: Interplay of surface roughness with surrounding gas Phys. Rev. Lett. 76:066311

Xu L, Zhang WW, Nagel SR. 2005. Drop splashing on a dry smooth surface. Phys. Rev. Lett. 94:184505

Yarin AL, Weiss DA. 1995. Impact of drops on solid surfaces: self-similar capillary waves, and 
splashing as a new type of kinematic discontinuity. J. Fluid Mech. 283:141-73

Yarin AL. 2006. Drop impact dynamics: Splashing, spreading, receding, bouncing ... Annu. Rev. Fluid Mech. 38:159-92

Yeong YH, Burton J, Loth E, Bayer IS. 2014. Drop impact and rebound dynamics on an inclined superhydrophobic surface. Langmuir 30:12027-38

Yokoi K, Vadillo D, Hinch J, Hutchings I. 2009. Numerical studies of the influence of the dynamic contact angle on a drop impacting on a dry surface. Phys. Fluids 21:072102

Yokoi K. 2011. Numerical studies of droplet splashing on a dry surface: triggering a splash with the dynamic contact angle. Soft Matter 7:5120

Yoon SS, Jepsen RA, Nissen MR, O'Hern TJ. 2005. Experimental investigation on splashing and nonlinear fingerlike instability of large water drops. J. Fluids Structures, 23:101-115 